University of Nebraska - Lincoln

DigitalCommons@University of Nebraska - Lincoln

Publications, Agencies and Staff of the U.S.

Department of Commerce

U.S. Department of Commerce

2010

\title{
Regional seismicity of the Mid-Atlantic Ridge: observations from autonomous hydrophone arrays
}

\author{
N. Simão \\ École Normale Supérieure, simao@geologie.ens.fr \\ J. Escartín \\ Institut de Physique du Globe de Paris \\ J. Goslin \\ Institut Universitaire Européen de la Mer \\ J. Haxel \\ Oregon State University \\ M. Cannat \\ Institut de Physique du Globe de Paris \\ See next page for additional authors
}

Follow this and additional works at: https://digitalcommons.unl.edu/usdeptcommercepub

Part of the Environmental Sciences Commons

Simão, N.; Escartín, J.; Goslin, J.; Haxel, J.; Cannat, M.; and Dziak, R., "Regional seismicity of the MidAtlantic Ridge: observations from autonomous hydrophone arrays" (2010). Publications, Agencies and Staff of the U.S. Department of Commerce. 315.

https://digitalcommons.unl.edu/usdeptcommercepub/315

This Article is brought to you for free and open access by the U.S. Department of Commerce at DigitalCommons@University of Nebraska - Lincoln. It has been accepted for inclusion in Publications, Agencies and Staff of the U.S. Department of Commerce by an authorized administrator of DigitalCommons@University of Nebraska - Lincoln. 


\section{Authors}

N. Simão, J. Escartín, J. Goslin, J. Haxel, M. Cannat, and R. Dziak 


\title{
Regional seismicity of the Mid-Atlantic Ridge: observations from autonomous hydrophone arrays
}

\author{
N. Simão, ${ }^{1,2 *}$ J. Escartín, ${ }^{3}$ J. Goslin, ${ }^{1,2}$ J. Haxel, ${ }^{4}$ M. Cannat ${ }^{3}$ and R. Dziak ${ }^{4}$ \\ ${ }^{1}$ Université Européenne de Bretagne, Université de Brest, Brest, France. E-mail: simao@geologie.ens.fr \\ ${ }^{2}$ Institut Universitaire Européen de la Mer, CNRS, UMR6538 Domaines Océaniques, Plouzané, France \\ ${ }^{3}$ Institut de Physique du Globe de Paris, CNRS, UMR7154 Géosciences Marines, Paris, France \\ ${ }^{4}$ Oregon State University, PMEL-NOAA, Hatfield Marine Science Center, Newport OR, USA
}

Accepted 2010 September 16. Received 2010 September 16; in original form 2010 May 7

\begin{abstract}
SUMMAR Y
Autonomous hydrophones arrays are an excellent tool for monitoring mid-ocean ridge seismic activity. The major advantage of using arrays of autonomous hydrophones for recording deepocean ridge earthquakes is its low magnitude detection thresholds achievable using hydroacoustic techniques. Regional analysis of the detection thresholds of the different autonomous hydrophones arrays deployed along the Mid-Atlantic Ridge reveals the strong influence of the detection threshold in the number of recorded events and it must be taken into account in any further analysis. In this study, the analysis of both autonomous hydrophones and teleseismically detected Mid-Atlantic Ridge seismicity reveals that the background seismicity from the relatively short recording periods of the autonomous hydrophones mimic the results of the much longer teleseismic recording. It also reveals that seismicity generally cluster at both the segment scale and on Mantle Bouguer Anomaly maxima. The big majority of these clusters seem to be related to dyke intrusions and propagation along the Mid-Atlantic Ridge. These dyke intrusions interact with the mainshock-aftershock sequences. The seismic sequences mainshock-aftershock analysis reveals that the strength of the faults is highly influenced by the mode, or style, of faulting. Detachment faults, which are ubiquitous along the Mid-Atlantic Ridge, can produce more prolific shorter duration seismic sequences revealing faster and reduced strain releases in comparison to higher angle normal faults. This reduced strain release is most likely to occur due to the presence of higher levels of serpentinization on detachment faults. Higher levels of serpentenisation can also promote an aseismic transient slip on the mainshock-aftershock sequences.
\end{abstract}

Key words: Time series analysis; Spatial analysis; Seismicity and tectonics; Rheology and friction of fault zones; Mid-ocean ridge processes; Atlantic Ocean.

\section{INTRODUCTION}

Historically, there have been few regional observations of earthquake sequences along mid-ocean ridges largely due to the limited spatial coverage provided by the global seismic networks. The Pacific Marine Environmental Laboratory's (PMEL's) regional Autonomous Hydrophones $(\mathrm{AuH})$ arrays have provided an improvement in the detection capabilities of seismicity, making it possible to characterize the temporal and spatial earthquake patterns in remote oceanic areas. Hydrophone earthquake source locations are derived from distinct $T$-wave arrivals recorded by the AuH arrays (Fox et al. 2001). These source locations represent the point where $T$-wave energy enters the sound channel once this acoustic energy is radiated into the water column from seismic phases at the seafloor-ocean in-

* Now at: The École Normale Supérieure, CNRS, UMR8538 Géologie, Paris, France. terface. This energy is characterized by a Source Level (Dziak 2001; Fox et al. 2001) which represents sound pressure in decibels at a reference distance of $1 \mathrm{~m}$ from the source location. Despite the high incidence angles that should result from the large density contrast between seafloor and water column, $T$-phase conversion and propagation in the Sound Fixing and Ranging (SOFAR) channel is made possible through low take-off angle conversion mechanisms, such as multiple reflections (Talandier \& Okal 1998), mode coupling (Park et al. 2001) and scattering from the seafloor (Yang \& Forsyth 2003). These conversion mechanisms illustrate the complexity surrounding $T$-phase excitation, making it difficult to directly estimate the magnitude, hypocentre and the physical parameters of the earthquake (Williams et al. 2006). Despite these complexities, the low acoustic attenuation properties of the sound channel allow for a lower detection threshold of earthquakes along the Mid-Atlantic Ridge (MAR) by 1.5 magnitude units relative to land-based seismic networks (Dziak et al. 2004b). Furthermore, Bohnenstiehl \& Tolstoy 
(2003) and Pan \& Dziewonski (2005) demonstrate that earthquakes source locations recorded by four or more $\mathrm{AuH}$ and within the arrays are more accurate than the land based derived locations and can therefore be used for detailed studies of the low level seismicity.

In early 1999 NOAA/PMEL laboratory deployed one AuH array (MARA) in the MAR between $16^{\circ} \mathrm{N}$ to $34^{\circ} \mathrm{N}$ (Smith et al. 2002) to improve the monitoring of the MAR seismicity, which provides information as far south as the Walvis Ridge (Haxel \& Dziak 2005). The deployment lasted until mid 2005. The 'Domaines Oceaniques' laboratory deployed another AuH array (SIRENA) in the MAR, in the region north of the Azores between $40^{\circ} \mathrm{N}$ and $50^{\circ} \mathrm{N}$ monitoring the seismicity as far north as the Reykjanes Ridge (Goslin et al. 2005). The duration of the deployment was 15 months, ending in mid 2003. Later, within the context of the Monitoring the Mid-Atlantic Ridge (MoMAR) project, a third AuH array was deployed south of the Azores (MARCHE). The deployment began in mid 2005 and ended in mid 2008. The nine years of AuH deployment along the MAR provided a comprehensive data set covering most of the northern MAR, permitting researchers to observe major seismic crises (Bohnenstiehl et al. 2002; Dziak et al. 2004a; Goslin et al. 2005; Haxel \& Dziak 2005) and to better understand the spatial distribution of seismicity in the MAR (Bohnenstiehl et al. 2003; Escartín et al. 2003b, 2008; Pan \& Dziewonski 2005; Smith et al. 2003, 2006).

This paper analyses this unique long record of seismicity to determine if the regional distribution of seismicity previously determined from both teleseismic events and $\mathrm{AuH}$ deployments, with areas of seismic quiescence and ridge sections that are very active, is maintained, or reflects instead a temporal variability. To study this, a long wavelength comparative analysis of hydroacoustic versus teleseismic based data sets was made in the MAR from $12^{\circ} \mathrm{N}$ to $52^{\circ} \mathrm{N}$. To be able to evaluate variations in seismicity across space and time, recorded in different sectors of the MAR and to interpret those variations, the detection thresholds of the $\mathrm{AuH}$ catalogue needs to be taken into account because it may vary with time according to the geometry of each deployment. The long wavelength comparative analysis of hydroacoustic versus teleseismic based data sets was made using declustered catalogues, meaning that we compared only the background seismicity, not associated to time limited seismic clusters, representative of a short period variability in the seismicity record. With a declustered data set it was then possible to compare the different temporal recordings of the various arrays deployed in the MAR during the nine-year $\mathrm{AuH}$ experiment and compare them to the 40-year span International Seismological Centre (2007) catalogue obtained for the MAR.

In the $12^{\circ} \mathrm{N}$ to $52^{\circ} \mathrm{N}$ region, the MAR exhibits major features, such as the Fracture Zones and the Azores plateau. The influence of the Azores on the MAR has already been observed and discussed by several authors (Cannat et al. 1999; Detrick et al. 1995; Escartín et al. 2001a; Gente et al. 2003; Maia et al. 2007; Lin et al. 1990; Thibaud et al. 1998). It consists of a trend of wavelengths larger than $100 \mathrm{~km}$, with larger positive to negative Mantle Bouguer Anomaly (MBA) values as the ridge approaches the Azores and clear modification on the ridge morphology, showing a shallower and narrower axial valley (Cannat et al. 1999; Gente et al. 1995). Smaller systematic features are also found at segment scale, like for example, along-axis depth variations, MBA variations within the segments that constitute it or the axial valley dimensions (Detrick et al. 1995; Hooft et al. 2000; Lin et al. 1990; Searle et al. 1998; Sempéré et al. 1995; Thibaud et al. 1998). One question this poses is, can these major and minor features of the MAR influence its seismicity? Another question is, are there systematic differences in seismicity related to the two main modes of accretion identified along the MAR, one volcanically dominated with formation of abyssal hills, the other tectonically dominated with exhumation of deeply derived gabbros and peridotites along detachment faults? With the advent of the AuH monitoring of the MAR seismicity, another observed systematic feature was the temporal seismic stripes and gaps described in Smith et al. (2003), related to regions of the MAR with near continuos seismicity activity and zones which are almost seismically inactive. These seismic stripe/gap pattern was later associated with the modes of spreading and faulting in the MAR (Escartín et al. 2008; Smith et al. 2006). These seismic stripes and gaps were not observed in land based catalogues due to their higher detection threshold. In this paper, we analysed $\mathrm{AuH}$ recorded earthquake mainshock-aftershock sequences to bring additional insights to the understanding of the relationship between modes of extension and seismic activity.

\section{METHODS}

In total from 1999 February until 2007 August nearly 15000 events were located in the northern part of the MAR by three AuH arrays deployed on the MAR. They occurred in a region delimited by the Marathon Fracture Zone near $12^{\circ} \mathrm{N}$, the Charlie Gibbs Fracture zone near $52^{\circ} \mathrm{N}$ and a cross section region delimited by the magnetic anomaly 3A (5.69 Myr) (Fig. 1). A land-based catalogue

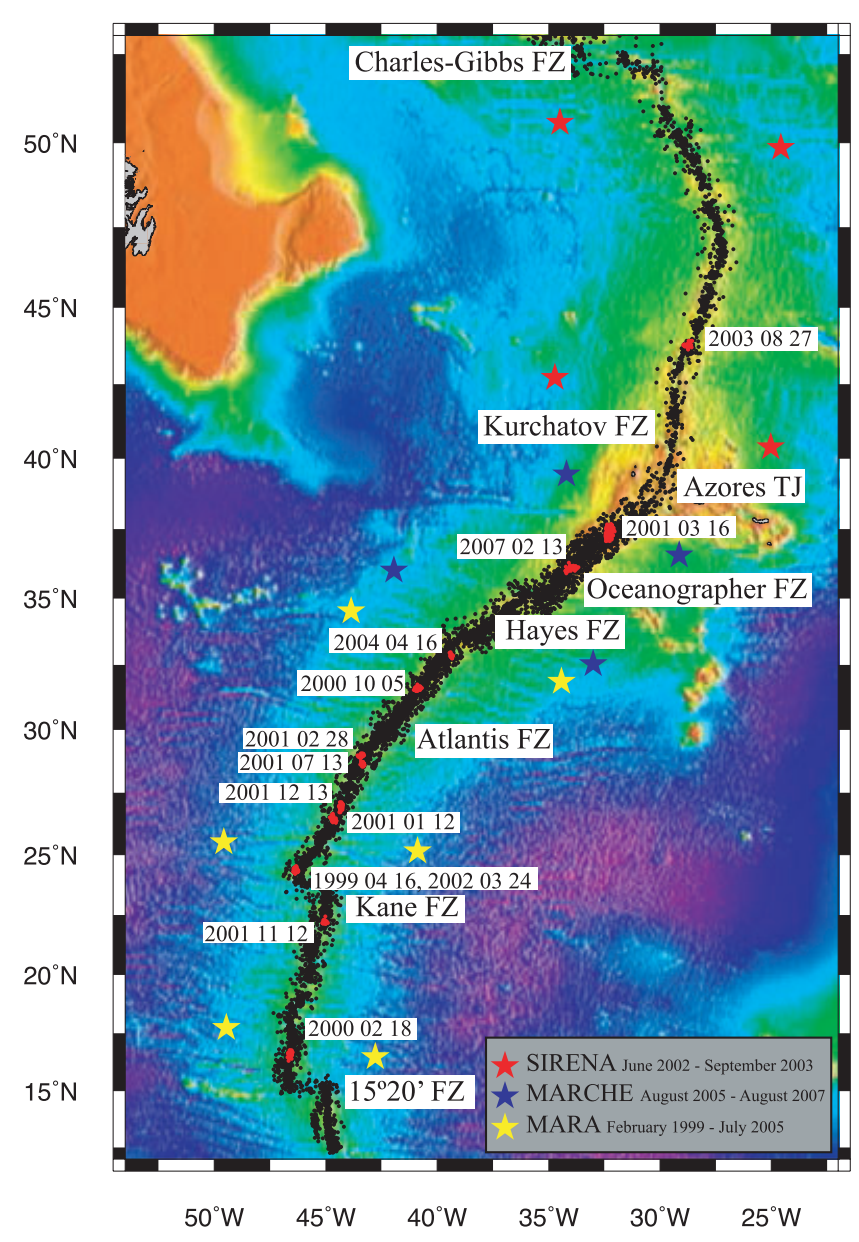

Figure 1. MAR AuH recorded seismicity. Red circle clusters represent the identified sequences. Yellow stars show the locations of the MARA AuH. Blue stars show the locations of the MARCHE AuH. Red stars show the locations of the SIRENA AuH. 


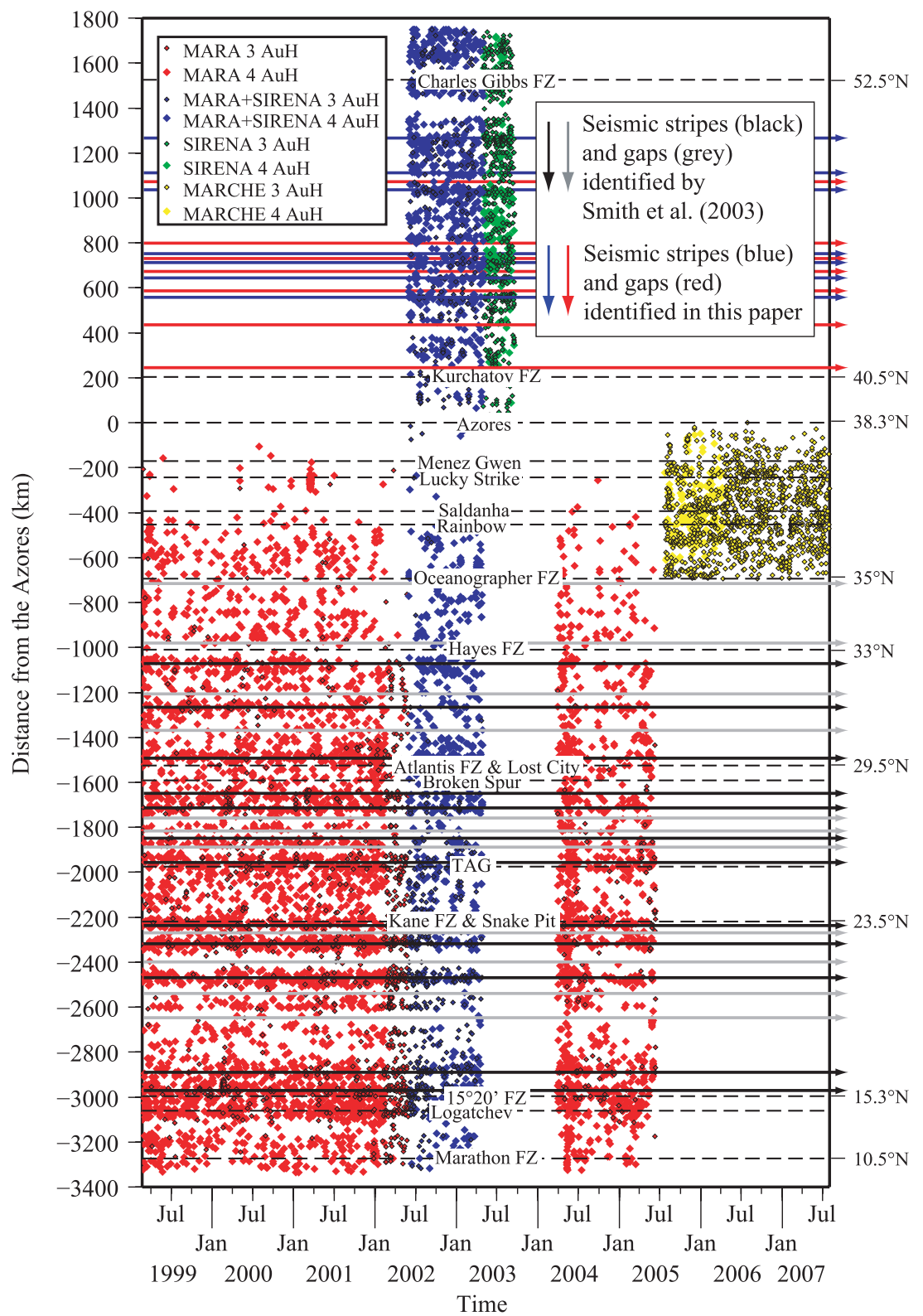

Figure 2. Time distance plot of all AuH recorded seismicity for the MAR. The gap which occurred between 2003 May and 2004 May, south of the Azores, is the result of AuH technical problems during that deployment.

was also created between 1964 to the middle of 2007. International Seismological Centre (2007) (ISC) data was used for the hypocentral locations. Global Centroid Moment Tensor Project (http://www.globalcmt.org) based information was used for the focal mechanisms. When referring to magnitudes, priority goes first to $M \mathrm{w}$, second to $M \mathrm{~s}$ and third to mb (Bohnenstiehl et al. 2002). We thus created the most homogeneous catalogue possible, with a common detection threshold for the studied section of the MAR. Great-arc distances in kilometres were computed between the event locations found by the $\mathrm{AuH}$ and land based networks and an origin defined at the Azores Triple-Junction (Luis et al. 1994). The tectonic rotation poles between the different plates were used as centres of the great arcs. Three rotation poles were used (Sella et al. 2002): the Euroasia-North America rotation pole for great arcs north of the Azores Triple-Junction $\left(38.9^{\circ} \mathrm{N}\right)$; the North America-Nubia rotation pole for great arcs between $14.3^{\circ} \mathrm{N}$ and $38.9^{\circ} \mathrm{N}$ and the Nubia-South America rotation pole for great arcs south of the $14.3^{\circ} \mathrm{N}$. The distribution of AuH seismicity in a time versus distance to the Azores Triple-Junction plot are shown in Fig. 2.

\subsection{Detection thresholds analysis and Gutenberg Richter Law}

Detection thresholds of AuH catalogues may be dependent on the distance between the events and the array, topographic blockage or illumination due to the specific nature of the $T$-phases (Dziak 2001; Fox et al. 2001; Williams et al. 2006) and instrument failure during the acquisition period. To evaluate the detection thresholds in the AuH catalogue, a $T$-phase frequency-size relationship variation of the Gutenberg-Richter Law (Bohnenstiehl et al. 2002; Gutenberg \& Richter 1944) was used:

$\log (n)=a_{t}+b_{t} S L_{c}$. 
In this frequency-size relationship variation of the GutenbergRichter Law, AuH Source Levels were used instead of the traditional seismic magnitudes. The Source Levels scale ranges from $\sim 190$ to $\sim 240 d B$. The Source Level of completeness $S L_{c}$ is the minimum Source Level for which the catalogue is considered complete, $n$ is the number of events with Source Level bigger than the Source Level of completeness $S L_{c}, b_{t}$ is representative of the frequency-size relationship and $a_{t}$ is dependent from the total number of events. To resolve the equation, the maximum likelihood method was used (Ogata \& Katsura 1993; Woessner \& Wiemer 2005). Uncertainties in $S L_{c}$ and $b_{t}$ were estimated using a bootstrap approach (Schorlemmer et al. 2003). The completeness is a measure of quality and detectability for a catalogue and can be used to illustrate the temporal variations due to improvements or failures in the sensors or environmental changes surrounding the array. Several studies have related the more orthodox $b$-values to physical properties such as stress components, material homogeneity and pore pressure (Shaw 1995; Scholz 1990). The traditional $b$-value varies normally in the proximity of the value 1 . More recently, high $b$ value anomalies were proposed to indicate lack of homogeneity in the analysed catalogues (Kagan 2002) (different fault mechanisms), near field proximity to active magma chambers (Wiemer \& Wyss 2002; Wyss et al. 2001a,b) and to show a dependency with the strain regime of the fault mechanism (Schorlemmer et al. 2005). In this case, the completeness $S L_{c}, a_{t}$ and $b_{t}$ depend on the energy liberated by the earthquake during the conversion of the seismic phases into $T$-phases and on the propagation path to the sensors. Due to the different scale range used, $b_{t}$ is on the order of 10 times smaller than the $b, S L_{c}$ and $a_{t}$ are several orders greater than the traditional $M_{c}$ and $a$. The much higher number of events recorded by the $\mathrm{AuH}$ facilitates the observation of variations in the detection threshold across space and time. This can then be used as a measure of quality and detectability for the $\mathrm{AuH}$ catalogue. Fig. 3 shows the variation in $S L_{c}$ both along-axis and in time.

\subsection{Cluster analysis and correlation between seismicity profiles}

The Single Link Cluster technique of Frohlich \& Davis (1990) and Davis \& Frohlich (1991a,b) was employed to identify discrete time and space clusters of seismic activity within the extensive MAR $\mathrm{AuH}$ and teleseismic earthquake catalogues. The process consists of linking individual events to its nearest neighbour using the metric $D=\sqrt{d^{2}+t^{2}}$ to form sub-groups. $d$ is the distance in kilometres (including depth for the teleseismic catalogue) between two events and $t$ is the time in decimal days between two events. This association process continues by linking each sub-group to its nearest neighbour sub-group, recursively, until the last link equals the number of events in the catalogue, minus one. Nyffenegger \& Frohlich (2000) defined the optimal $D$ producing the best score for separating the different clusters $D_{\text {best }}=0.8 \bar{D}$, where $\bar{D}$ is the median link of all links computed. Median links were computed for each $\mathrm{AuH}$ array configuration. The analysis was made for events with a Source Level bigger or equal to the completeness level and for events recorded by at least 4 hydrophones. Using this approach, $\sim 55$ per cent of the events in the analysed catalogue are considered clustered. In Figs 4(a) and (b) the clusters were dissociated from the catalogue. In Fig. 5, two AuH profiles were produced with different data sets for the region between the Azores and the Oceanographer Fracture Zone, the first the AuH1 uses MARA data and the second the AuH2 uses data from MARCHE. The AuH final declustered seismicity profiles result from the normalization of data from the

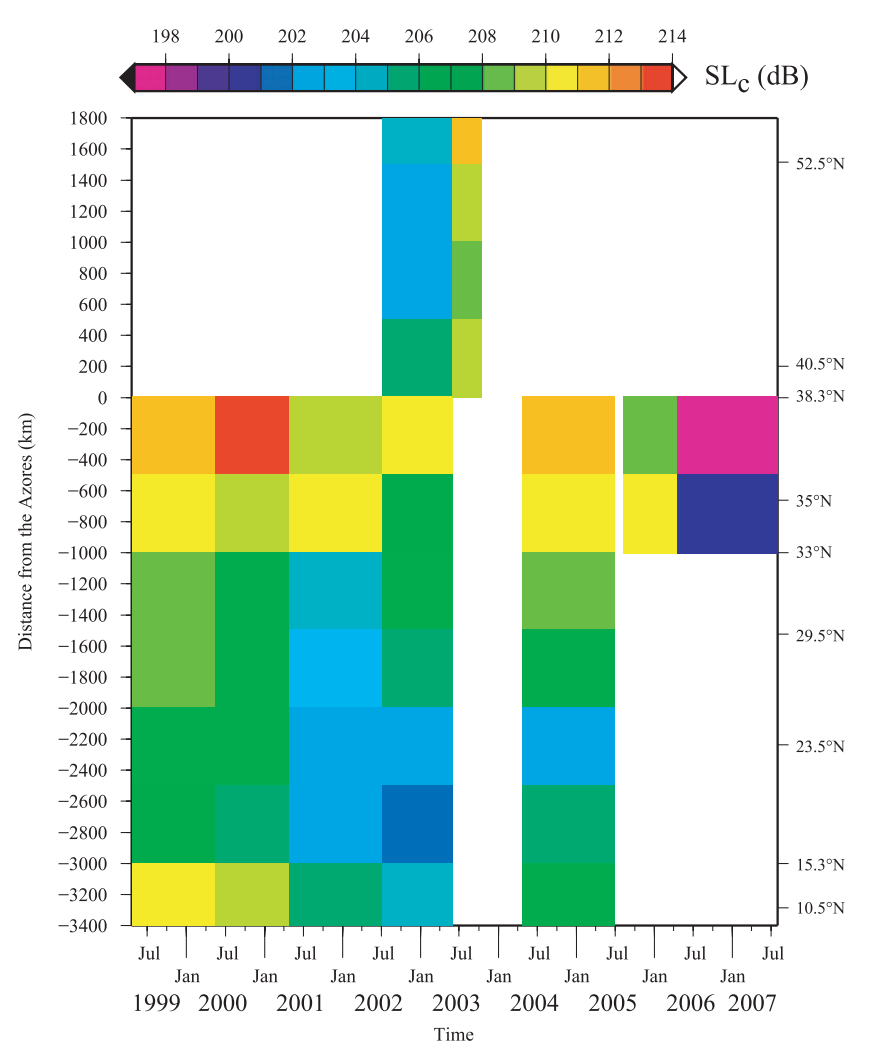

Figure 3. The $S L_{c}$ temporal and spatial variation was computed on blocks of $500 \mathrm{~km}$ by cruise turnover times. This resolution was chosen so that enough events were used to make the $S L_{c}$ meaningful and also to illustrate how $S L_{c}$ changes between turnovers.

three different arrays to obtain an events/year versus distance curve. This result corresponds to the background seismicity along the ridge axis (Figs 4a,b and 5).

Following on from this process, the next step was to obtain profiles along the MAR of the distribution of the seismicity recorded both by the AuH and the land based networks. Seismicity profiles were then filtered using a Gaussian filter with widths varying between 100 and $300 \mathrm{~km}$. Fig. 5 displays the resulting profiles for a filter width of $200 \mathrm{~km}$. The Spearman rank correlation was used to obtain the correlation coefficient and its confidence level among the four profiles. Spearman's rank correlation coefficient is a type of correlation coefficient that represents the relationship between two variables that are measured on the same interval or ratio scale. The two sets of variables are ranked separately and the differences in rank, $d$, are calculated for each pair of variables. The equation is:

$r=1-6 \frac{\sum_{i=1}^{n} d_{i}^{2}}{n^{3}-n}$

where $n$ is the number of paired variables (Bevington \& Robinson 2003; Press et al. 1996). The Spearman rank correlation coefficient $r$ has low correlation for $r$ when $\leq 0.3$. An $r$ between 0.3 and 0.5 represents a moderate correlation factor, while $r \geq 0.5$ means the profile correlation is high.

\subsection{Modified Omori Law}

The method used to identify the clusters was the Single Link Cluster analysis, described above, but this time the declustered events were the ones that were dissociated from the catalogue. Once again in this analysis only events located by four or more hydrophones were 

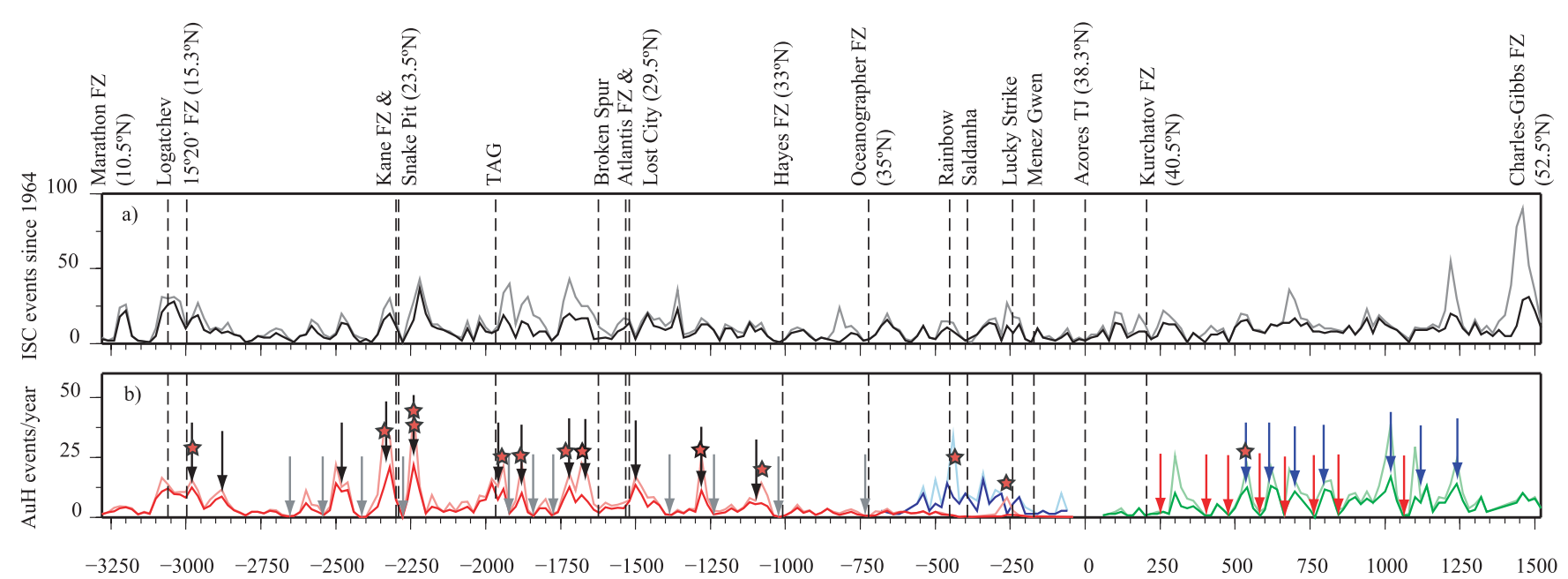

Distance from the Azores (km)
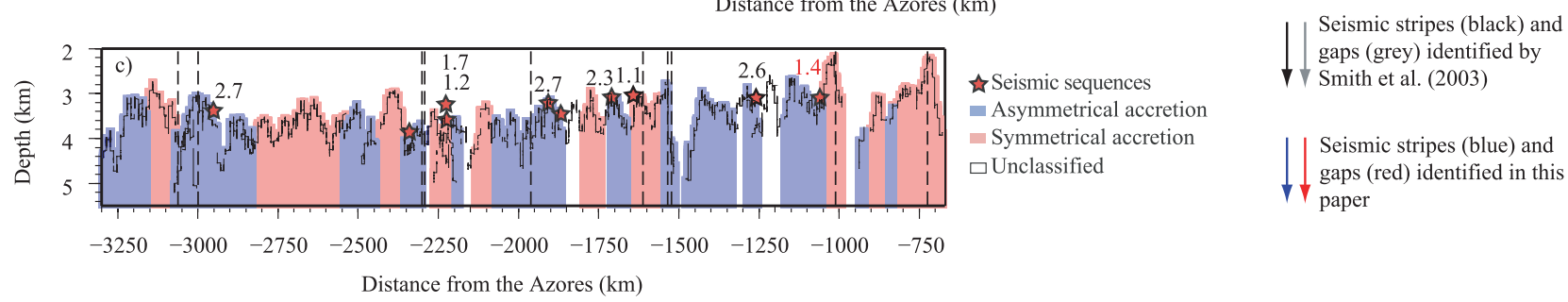

gaps (grey) identified by

$\checkmark$ Smith et al. (2003)

$\mid \begin{aligned} & \text { Seismic stripes (blue) and } \\ & \text { gaps (red) identified in thi }\end{aligned}$

$\downarrow$ gaps (

Distance from the Azores (km)

Figure 4. (a) MAR's teleseismicially recorded seismicity since 1964. Data obtained from International Seismological Centre (2007). Black profile is the declustered catalogue profile. Grey profile is the full catalogue. (b) MAR's AuH recorded seismicity since 1999. Red profile represents the declustered MARA array catalogue. Light red profile represents the full MARA array catalogue. Green profile is the declustered SIRENA array catalogue. Light green profile is the full SIRENA array catalogue. Blue profile represents the declustered MARCHE array catalogue. Light blue profile is the full MARCHE array catalogue. Seismic stripes, defined as areas of near continuous seismic activity and gaps, defined as bins of $20 \mathrm{~km}$ with less than 4 events per year. (c) Modified figure from Escartín et al. (2008) with sequences shown and respective $p$-values (numbers) of the sequences. Sequences recorded on detachment faulting regions have higher $p$-values than the ones recorded on the abyssal hill faulting regions. The red $p$-value (number) is from the sequence that was recorded at $30 \mathrm{~km}$ distance from the ridge.

incorporated, but no filtering was made in terms of Source Level. An exception was made just to note the occurrence of a mainshockaftershock sequence recorded on 2007 February 13 at the MAR segment north of the Rainbow vent field. Regions along the ridge where clusters of earthquakes occurred were identified. Next, after close visual inspection, the clusters of earthquakes were separated by region from the main catalogue and cumulative number of events time series and Source Level of the events time series were created for each discrete seismic cluster. Visual inspection of these time series reveals the candidates to be classified as mainshock-aftershock sequences (Figs 6c, d-13c, d) used in the Modified Omori Law.

Middle to large magnitude earthquakes generally produce aftershocks that are clustered in space and time around the mainshock and are generally referred to as mainshock-aftershock sequences. Analysis of the sequences was done using the Modified Omori Law (Kisslinger 1996; Utsu et al. 1995) and the Bohnenstiehl et al. (2002) size-frequency relationship for $T$-phases. The Modified Omori Law states that a mainshock at $t=0$ triggers an aftershock that in turn triggers its own aftershocks and so on till the stresses are relieved from the focal area.

In a seismic sequence a mainshock triggers aftershocks with an occurrence rate that decreases with time according to:

$n=\frac{K}{(c+t)^{p}}$.

Where $n$ is the cumulative number of earthquakes having occurred at time $t$ after the mainshock, $K$ is a constant that reflects the total number of events within the sequence and the size of the mainshock, $c$ reflects the rate of activity within the earliest part of the earthquake sequence, $t$ is the time and $p$ is the aftershock rate decay. This formulation gives the characteristic Modified Omori Law and suggests an interpretation of the aftershock decay rate of the fault in terms of changes in strain.

The aftershock decay rate clearly reflects the process of relaxing strain concentrations produced by the main fault rupture (Scholz 1990). Several authors have suggested that regions with higher crustal temperatures have a higher likelihood of being subjected to more rapid strain release and thus inducing $p$-values greater than 1 (Kisslinger 1996; Rabinowitz \& Steinberg 1998; Klein et al. 2006). A general state-variable constitutive formula for the occurrence rate of earthquakes with changes in the lithospheric strain properties was proposed by Dieterich (1994).

The Ogata \& Shimazaki (1984) method was used to fit the Modified Omori Law and a bootstrap approach was used to estimate errors in its parameters (Wiemer et al. 2002). This method allows the characterization of sequences that contain secondary aftershocksfollowing a major aftershock - that would change the rate at which the strain is released. It consists of fitting the seismic sequences by comparing four models. In the first model, the $p, c$ and $K$ are calculated for only one sequence. In the second model, two sequences are considered where $p$ and $c$ are the same in the two sequences and only $K$ changes. In the third model, two sequences are considered where $p$ is the same in the two sequences and where $c$ and $K$ change from one sequence to the other. In the fourth model, two sequences 


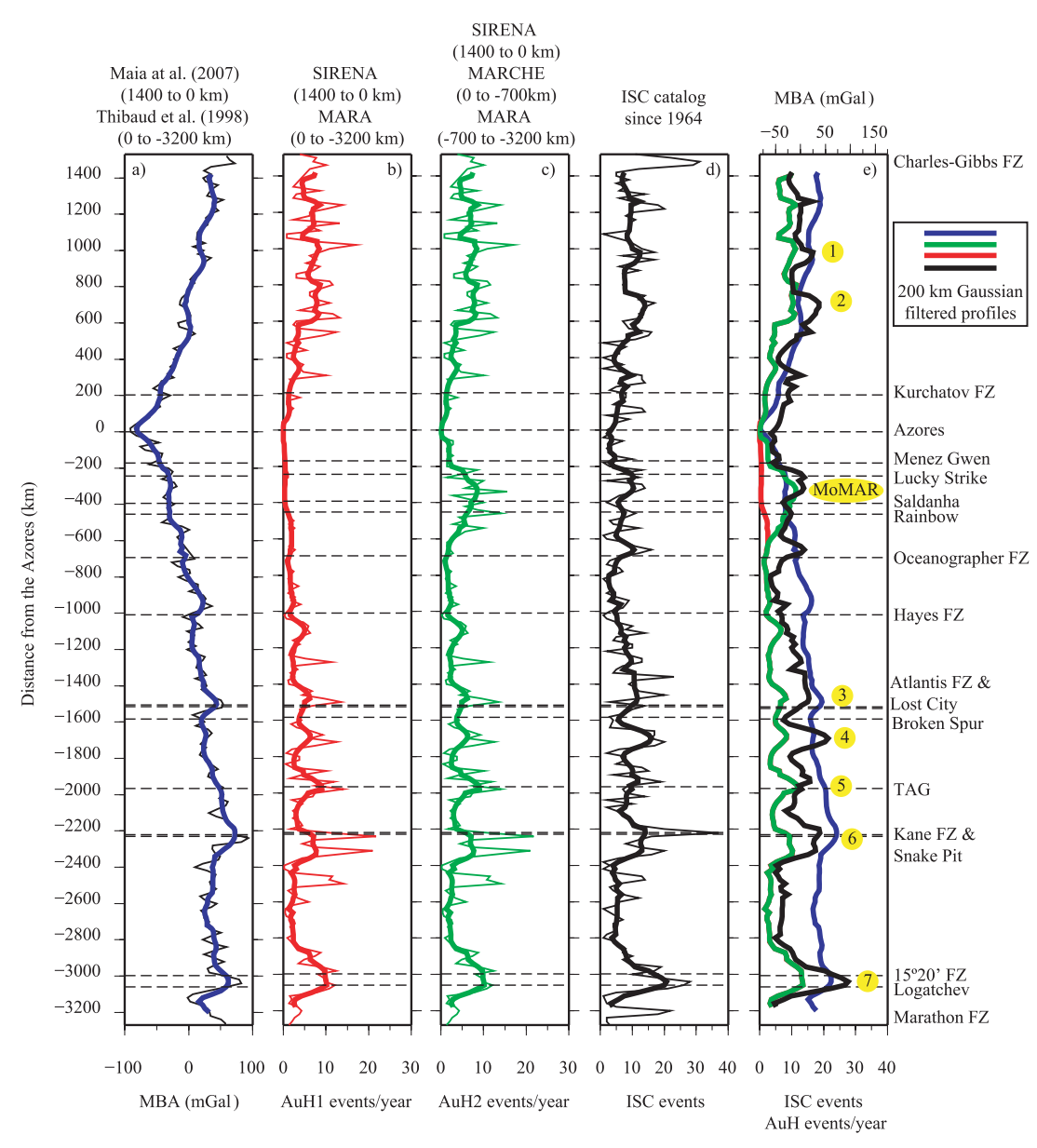

Figure 5. From left to right: (a) MAR's MBA (Thibaud et al. 1998; Maia et al. 2007) and filtered profile using a $200 \mathrm{~km}$ path filter. (b) and (c) AuH recorded events per year. The differences are: (b) MARA array data used for the region between the Oceanographer Fracture Zone and the Azores; (c) MARCHE array data used for the region between the Oceanographer Fracture Zone and the Azores. Red and green lines are the filtered profiles of the AuH seismicity using a $200 \mathrm{~km}$ path Gaussian filter. (d) Teleseismically recorded events in the last 40 years with its $200 \mathrm{~km}$ path Gaussian filtered profile represented by the fat black line. (e) Joint representation of all the filtered profiles. Yellow circles show the regions more seismically active of this part of the MAR.

are considered and $p, c$, and $K$ are different in the two sequences. The model that best fits the data was chosen following the Akaike Information Criterion:

$A I C=(-2)\{\max \log (L)\}+2 k$.

Where $L$ is the likelihood function and $k$ is the number of free parameters (Akaike 1973; Ogata 1983). The Akaike Information Criterion is not a measure of the goodness of fit of the chosen model, it is the parameter used to choose the best model. So the Kolmogorov-Smirnov test was used (Marsaglia et al. 2003; Miller 1956) to obtain a statistical goodness of fit between the model and the data. Using this test all Modified Omori Law fittings with a 95 per cent or higher confidence level were interpreted. The Kolmogorov-Smirnov goodness of fit test statistic is defined as:

$K S_{\text {stat }}=\max \left|F_{n}(x)-F(x)\right|$.

Where $F_{n}(x)$ and $F(x)$ are the cumulative distributions of the data and model distribution tested. $K S_{\text {stat }}$ varies between 0 and 1 , is a function of the difference between the data and the model and depends on the number of samples in the distribution.

The Modified Omori Law parameters can be biased if we assume the starting time of the sequence $T_{\min }=0$, due to the difficulty in detecting aftershocks in the first moments of the sequence, resulting from the mainshock coda duration and/or complex nature of the aftershocks (Nyffenegger \& Frohlich 1998; Ogata 1983). To avoid this, $T_{\min }$ was found to best fit the data in the period [ $\left.T_{\min }, T_{\max }\right]$.

Once the seismic sequences were discriminated, only sequences chosen with more than 40 events were retained, to ensure that $S L_{c}$ and the $b_{t}$ were meaningful (Wiemer \& Wyss 2002). For the Modified Omori Law calculations, only events with Source Levels bigger than the $S L_{c}$ were taken into account, as the $p$-value is independent of the earthquake magnitude only when the size of the events are bigger than $S L_{c}$ (Utsu et al. 1995). Using these parameters, it is possible to compare $p$-values from sequences detected by different arrays and different regions of the MAR. Following the discussion above, the $S L_{c}, b_{t}$ and $p$-value estimates will be used to characterize the earthquake mainshock-aftershock sequences.

\subsection{Mainshock-aftershock sequences distributions}

Hydroacoustically derived source locations used to identify earthquake sequences on the MAR were plotted in multi-beam bathymetry (Goslin et al. 1999; Smith et al. 2006; Thibaud et al. 1998) and MBA grids (Maia et al. 2007; Thibaud et al. 1998). This allows us to first, identify the ridge structures that are able to cause this kind of seismic activity and, second, correlate the 


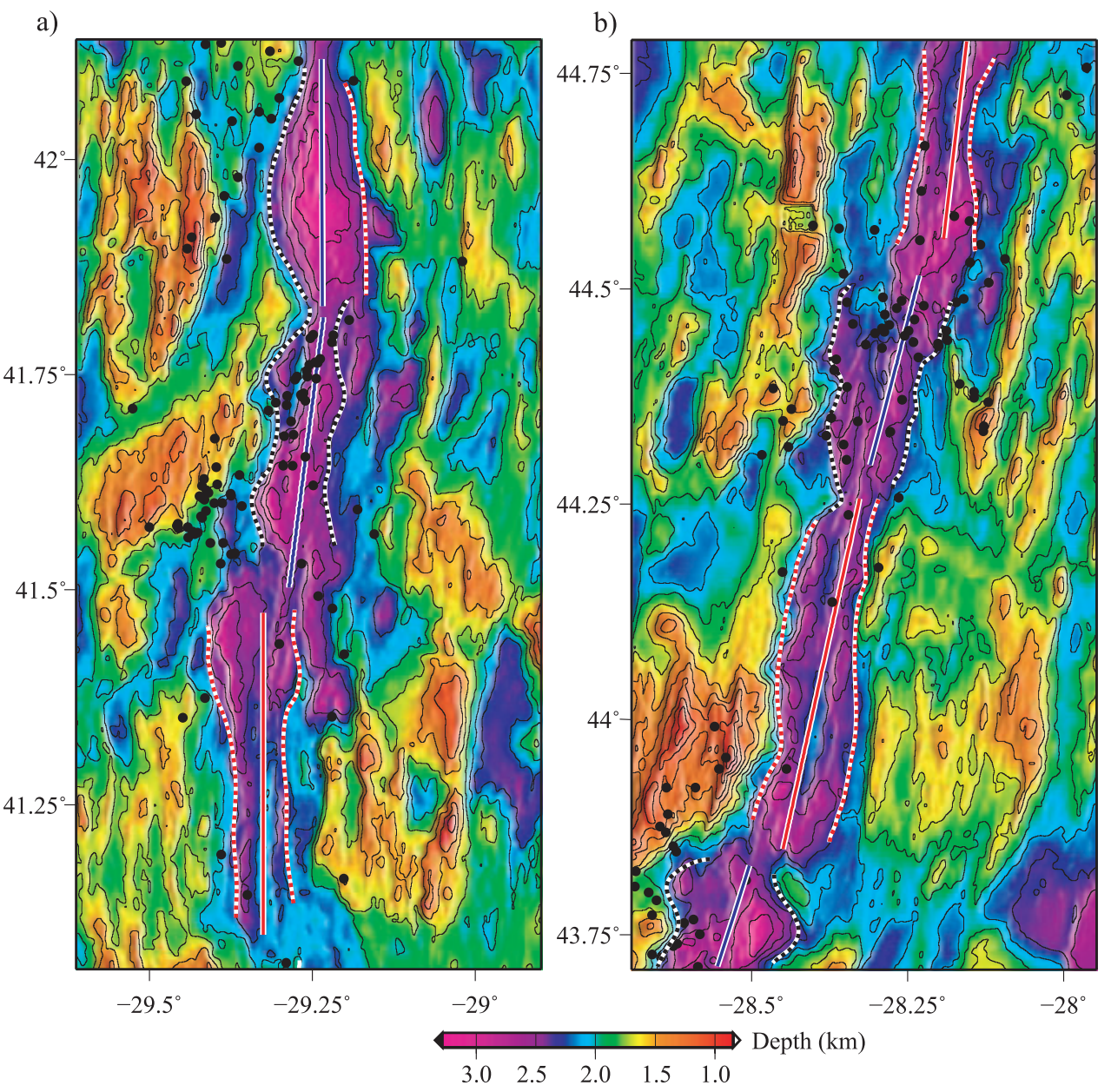

Figure 6. Two sections of the MAR north of the Azores using bathymetry obtained by Goslin et al. (1999). They illustrate the relationship between seismicity rates and modes of accretion. Asymmetric sections of the MAR are more seismically active than the symmetric sections. White segments are the MAR segments (Maia et al. 2007). Red segments represents symmetric accretion, blue segments represents asymmetric accretion, red dashed curves are ridgeward initiation of abyssal hills and black dashed curves are ridgeward initiation of detachment. (a) Section from $41^{\circ} \mathrm{N}$ to $42.125^{\circ} \mathrm{N}$. (b) Section from $43.75^{\circ} \mathrm{N}$ to $44.75^{\circ} \mathrm{N}$.

primary influence in terms of thermal regime and/or fault regime in the earthquake sequence's decay rate. The MBA narrower wavelength component is used to map local (segment scale) crustal thickness variations (Detrick et al. 1995; Maia et al. 2007; Lin et al. 1990; Thibaud et al. 1998).

The dimensions of the axial valley along a segment may be the parameter that more closely reflects the mechanical properties at the ridge axis (Cannat et al. 1999; Thibaud et al. 1998). The method of Thibaud et al. (1998) was the one used to calculate the width and depth of the axial valleys. In this method both the depth of the axial valley and the width of the axial valley are defined on one transverse profile and correspond respectively to the average height of the two walls between the inner floor and the crest of the median valley and the distance between the summit of the first steep walls on both sides of the axis. In this way, the axial valley depth and width will be used as parameters to evaluate the thermal state of the studied sequence's segments. To interpret the spatial distribution of the seismic sequences along the MAR segmentation, the segmentation of Maia et al. (2007) was used between $40^{\circ}$ and $45^{\circ} \mathrm{N}$, Thibaud et al. (1998) between $15^{\circ}$ and $40^{\circ} \mathrm{N}$ and Smith et al. (2008) between $12^{\circ}-15^{\circ} \mathrm{N}$. To have an estimate of the spatial location of each sequence with respect to the ridge morphology, the mean depth of the $T$-phase locations and the distance from the sequence mean position to the closest segment axis were calculated (Table 1).

\section{RESULTS}

\subsection{Detection limits and uncertainties of $\mathrm{AuH}$ arrays}

A first comparative analysis was made between the declustered land based catalogue and the declustered $\mathrm{AuH}$ catalogues that included events localized by three hydrophones. This first approach clearly showed a worse correlation between these seismicity profiles in comparison to the later analysis made using $\mathrm{AuH}$ catalogues composed of events recorded by at least four hydrophones (Section 3.2). Correlations values between ISC and $\mathrm{AuH} 1$ varied between 0.3 and 0.4 (99.95 per cent confidence level) on the $100-300 \mathrm{~km}$ wavelengths. Correlations between ISC and $\mathrm{AuH} 2$ varied between 0.4 and 0.5 (99.95 per cent confidence level) on the $100-300 \mathrm{~km}$ wavelengths. This poorer correlation was clearly viewed both visually and through the Spearman rank analysis. This was conclusive in the decision to leave out of all analyses all events recorded by three hydrophones.

There is an apparent decrease from 200 to $600 \mathrm{~km}$ in the seismic activity (red MARA dots) south of the Azores (Fig. 2). This apparent decrease in seismicity existed only when the MARA array was active and disappeared when the hydrophones were moved north to the MoMAR region. Fig. 3 shows that for the MARA array the detection threshold $S L_{c}$ is higher for the region between the Azores 
a)

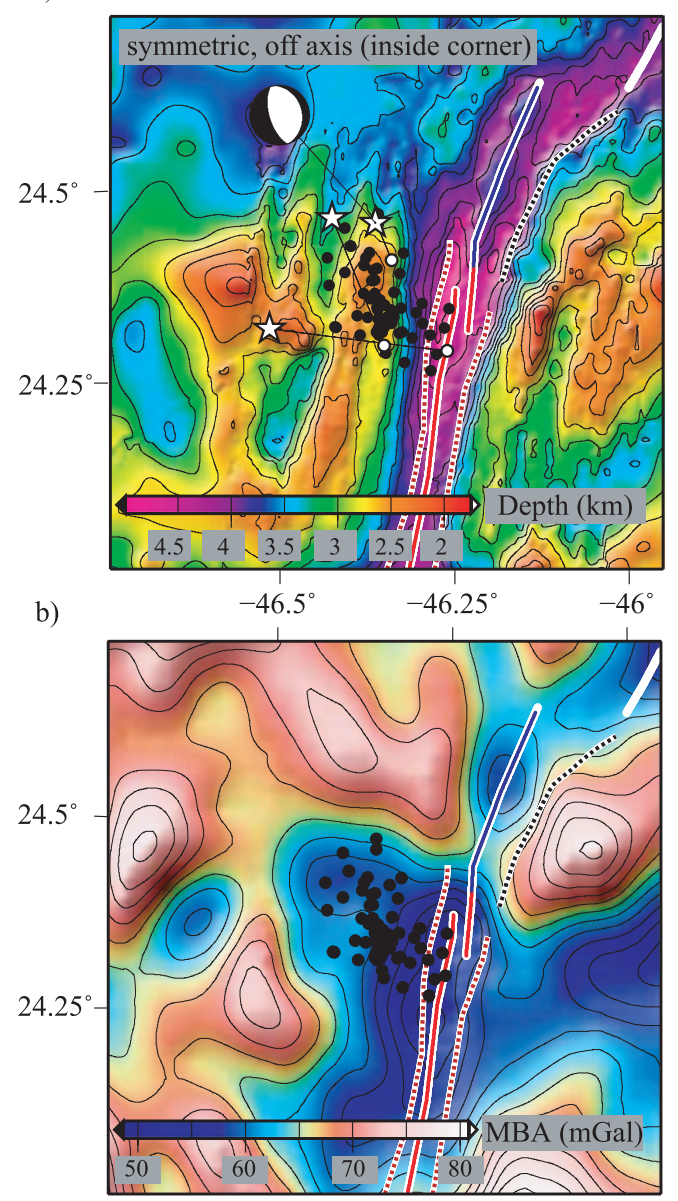

c)

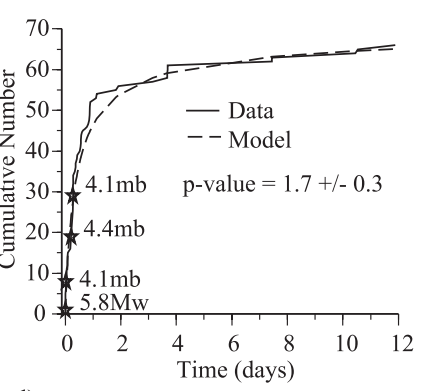

d)
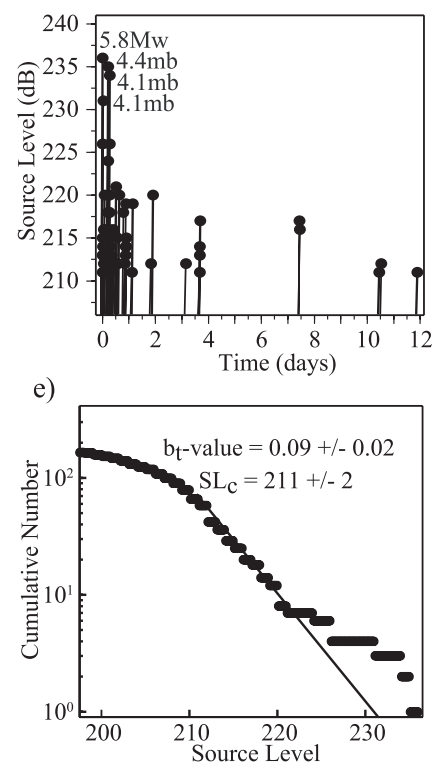

Figure 7. (a) Seismic sequence that started on 1999 April 6. Black circles are AuH recorded earthquakes. White stars are land based detected earthquakes. White segments are the MAR segments (Thibaud et al. 1998). Red segments represents symmetric accretion, blue segments represents asymmetric accretion, red dashed curves are ridgeward initiation of abyssal hills and black dashed curves are ridgeward initiation of detachment as defined by Escartín et al. (2008). Spreading mode and position across the segment is referred to in the picture. (b) MBA plot. (c) Modified Omori Law fit. (d) Source Level distribution across time. (e) Frequency-size relationship.

and the Oceanographer Fracture Zone. This increase in the $S L_{c}$ can go to a maximum value of $15 d B$ on the $\sim 190$ to $\sim 240 d B T$-phase scale range of energy. This suggests that this apparent decrease in seismicity is likely due to a deficient coverage of this region by the MARA array. The teleseismically recorded seismicity between the Oceanographer Fracture Zone and the Azores does not show any of the dramatic decrease in the seismicity rate that were observed by the MARA array. Furthermore, the AuH2 profile using data from MARCHE for the region between the Azores and the Oceanographer Fracture Zone correlates best with ISC than the AuH1 that uses the MARA data (Fig. 5). Spearman rank correlations between ISC and AuH1 varies between 0.4 and 0.5 on the $100-300 \mathrm{~km}$ wavelengths. Correlations between ISC and $\mathrm{AuH} 2$ varies between 0.6 and 0.7 on the $100-300 \mathrm{~km}$ wavelengths. All correlations were inside the 99.95 per cent confidence level. This can be used as an additional argument to the coverage problems of the MARA array on the region south of the Azores until the Oceanographer Fracture Zone.

The seismic stripe-gap pattern was not observed between the Azores and the Oceanographer Fracture Zone (Figs 2 and 4b). This can be due to relatively poorer locations obtained by the MARCHE array for this region (T.-K. Lau, personal communication, 2007).
Fig. 3 also shows a clear decrease in the $S L_{c}$ for the MARCHE array for the period after 2006 July. In this case the $S L_{c}$ strong variation between the two service cruises is caused by the fact that during the first deployment period the MARCHE array functioned as a four hydrophone array and that during the second deployment it was reduced to a three hydrophone array. Both hydrophone specifications and deployment locations remained the same in these two cases. This may be explained by the way the Source Level is computed by the $T$-phase analysis software (Dziak 2001; Fox et al. 2001) where Source Level is the mean value of all the source levels computed by each hydrophone. It also is a clear sign of the complexity of the propagation of the $T$-phases in this area.

North of $47^{\circ} \mathrm{N}(\sim 1350 \mathrm{~km})$ there is a huge seismic gap (Fig. 2) and a major difference in seismicity levels between the $\mathrm{AuH}$ and the teleseismic catalogues for the Charles-Gibbs Fracture Zone (Figs $4 \mathrm{a}$ and $\mathrm{b}$ ). This seems to suggest that this area is at the edge or beyond the best AuH array detection capacity. Also, the region near the Oceanographer Fracture Zone, reveals a high level teleseismic recorded seismicity, that contradicts the AuH records. This can reveal that the Oceanographer Fracture Zone region is at the extremity of the best detection capacities both for the MARA and MARCHE arrays. 

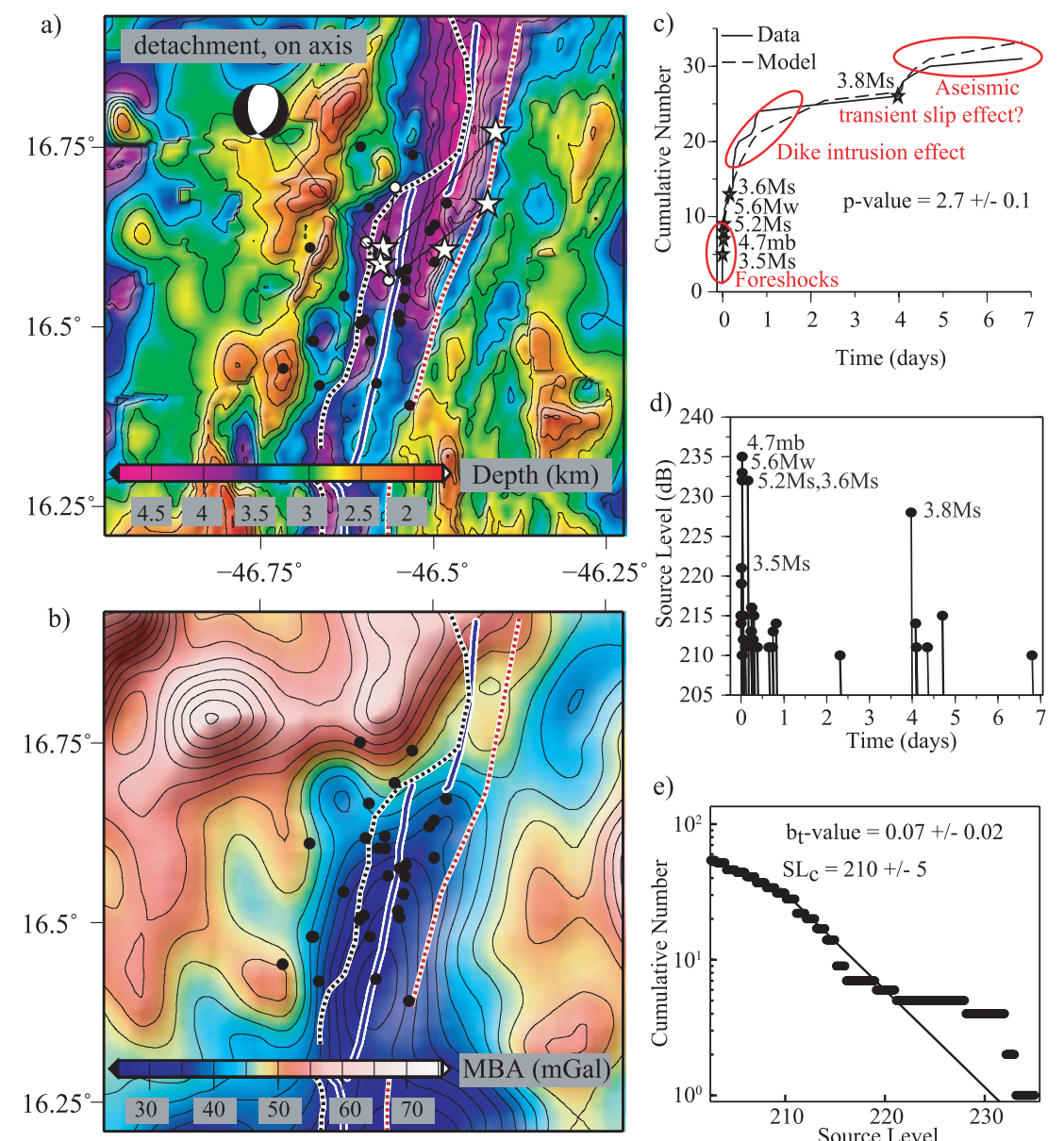

e)

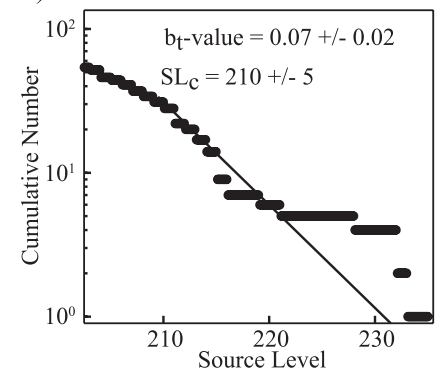

Figure 8. Seismic sequence that started on 2000 February 18.

\subsection{Regional analysis of seismicity}

North of the Azores eight areas span high levels of seismic activity across the AuH acquisition period (Figs 2 and 4b). Sections $50^{\circ} \mathrm{N}(\sim 1250 \mathrm{~km}), 48.6^{\circ} \mathrm{N}(\sim 1125 \mathrm{~km}), 47.8^{\circ} \mathrm{N}(\sim 1025 \mathrm{~km})$, $46^{\circ} \mathrm{N}(\sim 825 \mathrm{~km}), 45.3^{\circ} \mathrm{N}(\sim 700 \mathrm{~km}), 44.5^{\circ} \mathrm{N}(\sim 625 \mathrm{~km})$ (Fig. 6$)$, $43.8^{\circ} \mathrm{N}(\sim 550 \mathrm{~km})$ and $41.6^{\circ} \mathrm{N}(\sim 300 \mathrm{~km})$ (Fig. 6). With the exception of the section $41.6^{\circ} \mathrm{N}$ which shows a clear time variability in the level of seismicity, all the other sections have a near continuous level of seismic activity that took place during the AuH acquisition. Sections with a near continuous level of seismicity are the sections that reveal permanent regular seismic activity in time, scoring highly on the $20 \mathrm{~km}$ bin number of events histogram. The areas with near continuous seismicity also show some time variability in the base level of seismicity. This time variability in the base level of seismicity represents nearly half of all activity and, in fact, the most active sections of this part of the MAR are the sections where it occurred.

Figs 2 and 4(b) also show seismic gaps along the north part of the MAR. Seismic gaps are defined as sections that scored less than four events per year on the $20 \mathrm{~km}$ bin histogram. Major seismic gaps occur at $48.5^{\circ} \mathrm{N}(\sim 1075 \mathrm{~km}), 46.3^{\circ} \mathrm{N}(\sim 850 \mathrm{~km}) 45.7^{\circ} \mathrm{N}(\sim 775 \mathrm{~km})$, $44.7^{\circ} \mathrm{N}(\sim 675 \mathrm{~km}), 44.2^{\circ} \mathrm{N}(\sim 600 \mathrm{~km})$ (Fig. 6$), 43.2^{\circ} \mathrm{N}(\sim 475 \mathrm{~km})$, $42.5^{\circ} \mathrm{N}(\sim 400 \mathrm{~km})$ and $41.3^{\circ} \mathrm{N}(\sim 250 \mathrm{~km})$ (Fig. 6).

North of the $\sim 200 \mathrm{~km}$ region the MAR reveals a segmentation with well defined axial valleys (Maia et al. 2007), that are gener- ally associated with a intermediate to cold thermal regime (Cannat et al. 1999; Thibaud et al. 1998). Inspection of the bathymetry for the seismic stripe-gap pattern reveals that the seismically active regions, in comparison to inactive sections, are generally associated with stronger asymmetric morphologies which are themselves generally associated with a more asymmetric type of accretion (Fig. 6). This observed type of seismic activity mimics the spatio-temporal stripe/gap distributions observed south of the Oceanographer Fracture Zone (Smith et al. 2003), which were later linked to different modes of ridge accretion (Escartín et al. 2008).

The three years of extra observation for the region south of the Oceanographer Fracture Zone show the same spatial/temporal patterns as the ones observed by Smith et al. (2003) in the first two years of observation. Eleven regions were identified as seismic gaps and twelve regions including nearby regions of the Hayes, Kane and Oceanographer Fracture Zones were identified with stripes of seismic events.

Visual inspection of both the $\mathrm{AuH} 2$ (with events recorded by at least four hydrophones and data from the MARCHE array) (Fig. 5) and teleseismically recorded seismicity declustered profiles reveal a remarkable similarity. This similarity is reinforced by the strong correlation coefficients obtained in the Spearman rank analysis $(0.6$ to 0.7 on the $100-300 \mathrm{~km}$ wavelengths). Fig. 5 shows that the continuous seismicity signature of the MAR recorded in the 40 year catalogue obtained from the teleseismic records is equally well represented by the much smaller time span of the AuH arrays. This 

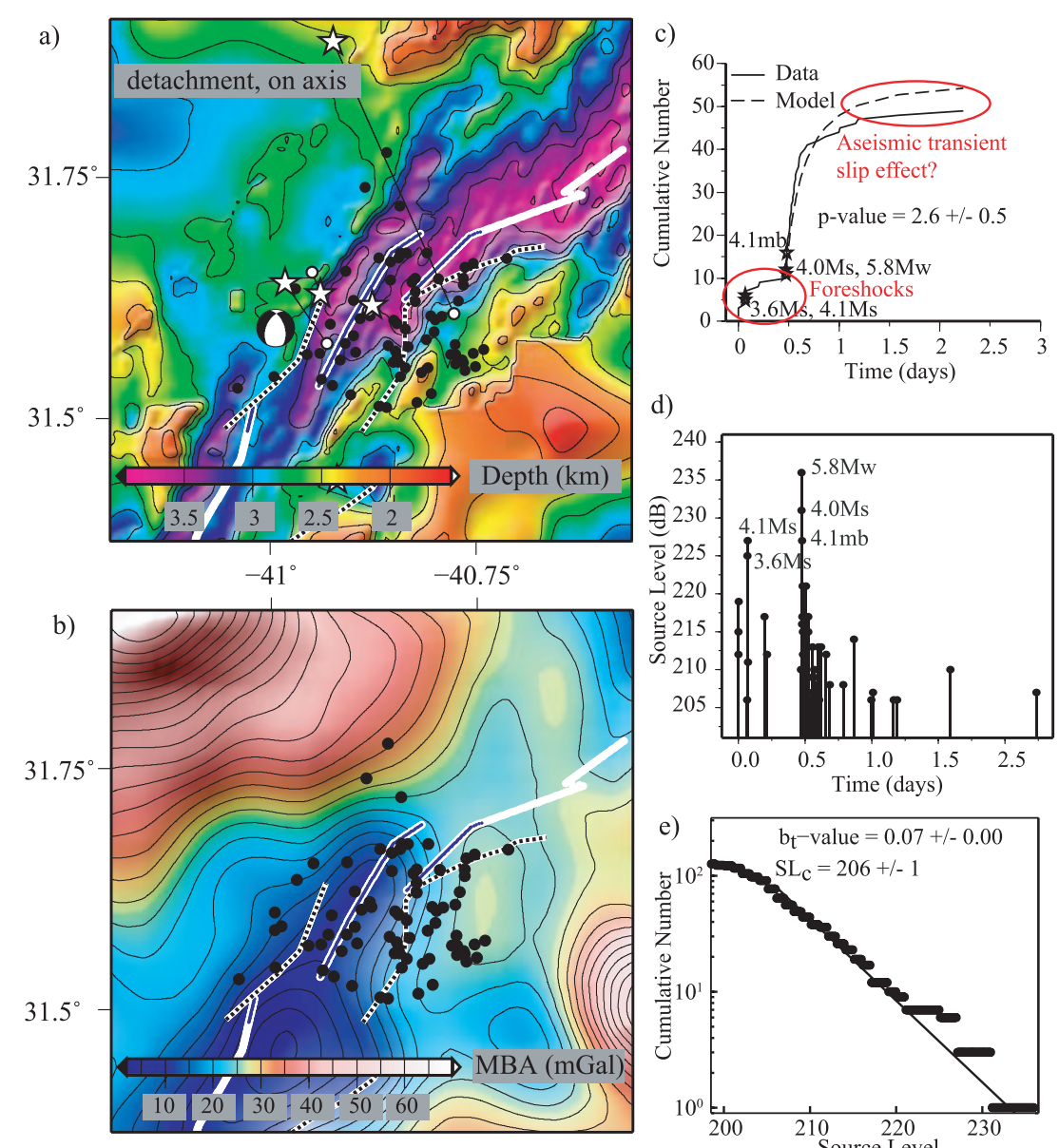

d)
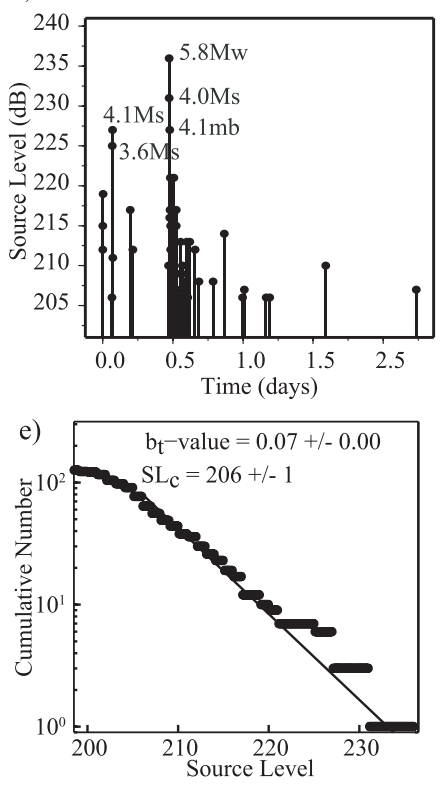

Figure 9. Seismic sequence that started on 2000 October 5.

implies that it is possible to infer with only a few deployments of temporally limited $\mathrm{AuH}$ arrays across different time periods (SIRENA array deployment lasted slightly more than one year) these continuous rates of seismic background activity on different sections of the MAR. It is also possible to observe that both the $\mathrm{AuH}$ and teleseismic arrays observed the same patterns of background seismic activity despite the different detection thresholds between the two (AuH arrays have a much lower detection threshold than land based arrays for these sections of the MAR).

Spearman rank correlation coefficient shows a poorer similarity between $\mathrm{AuH} 2$ and the MBA profiles (Fig. 5). Correlation coefficient varies between 0.4 and 0.5 on the $100-300 \mathrm{~km}$ wavelengths. Despite this poorer correlation the visual inspection of the profiles reveal that some features of the MAR that influence the MBA also influence the seismic rates. It shows that MAR's seismicity levels around the Azores $( \pm 200 \mathrm{~km})$ are very low both for the AuH2 and ISC and follow the trend of the MBA. This can be seen as an additional result of the influence that the Azores has on the rheology of the nearby ridge. In the same way, the Azores influences the MAR's morphology, indicated by the very shallow and narrow axial valley around this zone (Cannat et al. 1999; Detrick et al. 1995; Thibaud et al. 1998). North of the Azores two broad regions $\left(45^{\circ} \mathrm{N}\right.$ and $\left.48^{\circ} \mathrm{N}\right)$ reveal high levels of seismicity, in these two regions ( 1 and 2 in Fig. 5e) a lack of multi beam bathymetry limited further interpretation. South of the Azores six broad regions reveal high levels of seismicity. The first is the region known as MoMAR (Fig. 5e), home to the highest known density of hy- drothermal sources in mid oceanic ridges (Desbruyères et al. 2001; Humphris et al. 2002). These high levels of seismicity may be explained by the link shown by Escartín et al. (2008) between hydrothermal sources and detachment faulting. The region 3 in Fig. 5(e) is associated with the Atlantis massif and the Lost City vent field (Blackman et al. 2002; Kelley et al. 2005). A clear association between the detachment fault region associated with the core complex that justifies the high regional MBA and high levels of seismicity. The region 4 in Fig. 5(e) is a region associated with a non transform offset $\left(29^{\circ} \mathrm{N}\right)$, with high levels of seismicity occurring on both sides of the inside corner part of the offset. Two seismic mainshock-aftershock sequences were also recorded in this region. This region presents both abyssal hill faulting at its north and detachment fault structures in the south (Escartín et al. 2008). The region 5 in Fig. 5(e) is associated with a region that includes the TAG vent field (deMartin et al. 2007; Sohn et al. 2009). Again, the high levels of seismicity are linked to a region where detachment faults are known to exist. One mainshock-aftershock sequence was recorded in the region. The region 6 in Fig. 5(e) is located close to the Kane Fracture Zone and includes the Kane ocean core complex and the Snake Pit vent field (Dick et al. 2008; Gente et al. 1991; Tucholke et al. 1998). This region features abyssal hill structures to the north, where two mainshock-aftershock sequences where recorded and detachment fault structures in the south, where one mainshockaftershock sequence was recorded. High levels of seismicity and a regionally high MBA are associated with the oceanic core complex. Finally, the Logatchev region ( 7 in Fig. 5e), in the southern proximity 

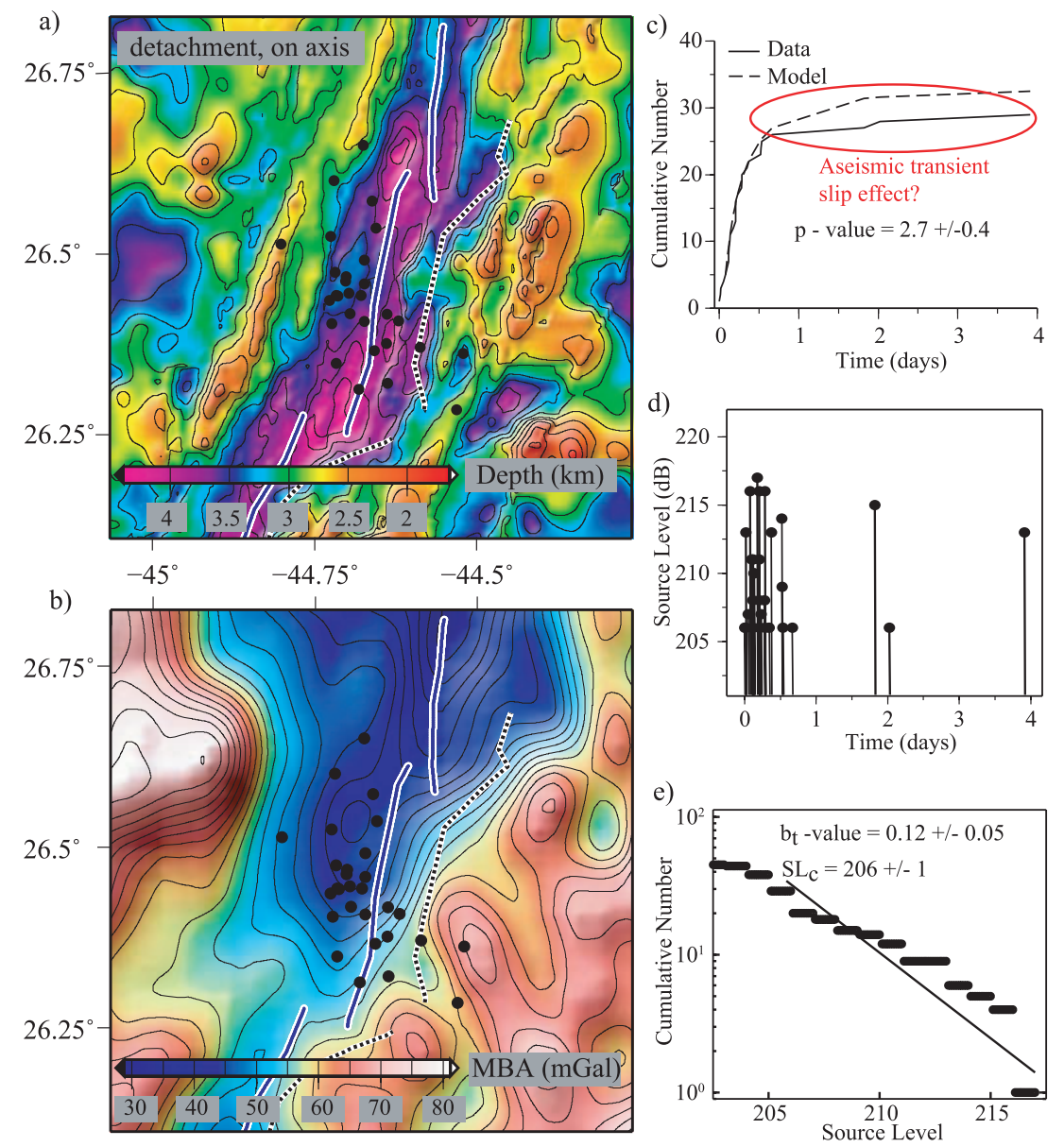

Figure 10. Seismic sequence that started on 2001 January 12.

of the $15^{\circ} 20^{\prime} \mathrm{N}$ Fracture Zone (Smith et al. 2008). This region also reveals a regional high MBA linked to a region with a high density of oceanic core complexes. One mainshock-aftershock sequence was recorded in this region.

\subsection{Mainshock-aftershock sequences}

The declustering process revealed more than 100 clusters all along the studied MAR region. Based on criteria described earlier, 10 new hydroacoustically derived mainshock-aftershock seismic sequences were identified in the last seven years of observation and were analysed using the methodology referred to above. These were interpreted with the two sequences reported in Bohnenstiehl et al. (2002) and the one reported in Dziak et al. (2004a). For the thirteen sequences, the previously described methodology was used to obtain frequency-size relationships (Table 2) and to fit the Modified Omori Law (Table 3). Two of the sequences need to be viewed as special cases and will not be interpreted in terms of the Modified Omori Law. The first is the sequence recorded on 2001 March that was located well outside the MARA array (Dziak et al. 2004a). The second, the sequence recorded on 2007 February, was only recorded in its entirety by three hydrophones during the second deployment of the MARCHE array.

Detected sequences occurred across the entire range of morphological features on the MAR. Sequences were recorded inside the axial valley (Figs 8a, 9a and 10a), or on segment flanks (Figs 7a, 11a, 12a, 13a and 14a). The sequence recorded in 2004 April in- dicates that the ridge lithosphere can be broken by active faulting, up to distances as great as $30 \mathrm{~km}$ from the ridge axis (Fig. 14a and Table 1). Figs 1 and 4(c) clearly indicate that most of the sequences were recorded between the Hayes and Kane Fracture Zones. This is not an artefact in the data that could be explained by the AuH having increased sensitivity in this region compared to other areas, as will be shown later when size frequency is discussed. The seismic sequences were recorded on segments with relatively wide $(12-26 \mathrm{~km})$ and deep $(632-1561 \mathrm{~m})$ axial valleys (Table 1). Despite considerable differences between segments' axial valley dimensions, all segments reveal an intermediate to cold thermal state (Thibaud et al. 1998). MBA grid plots of the sequences show that in all cases, sequences occurred on colder parts of the gravimetric segmentation (Figs $7 \mathrm{~b}$ to $14 \mathrm{~b}$ ). This seems to play well with the fact that the observed crustal thinning for typical bull's eye MBA segments is larger than the MBA anomaly would imply, suggesting that this typical segment end crust is less dense than the crust toward the centre (Tolstoy et al. 1993). This has been attributed to preferential thinning of the denser layer 3 , but could have contributions from serpentinization, greater fracturing of the crust, etc. The lithosphere and mantle below is colder and more brittle, hence the greater number of earthquakes observed.

The entire suite of earthquake sequences with 40 or more events went through a frequency-size analysis. For each sequence its $S L_{c}$ and $b_{t}$-value (Table 2) (Figs 7e to $14 \mathrm{e}$ ) were obtained. Seismic sequences recorded on 2000 October, 2001 January and 2001 November had most of their events located inside the axial valley at depths 

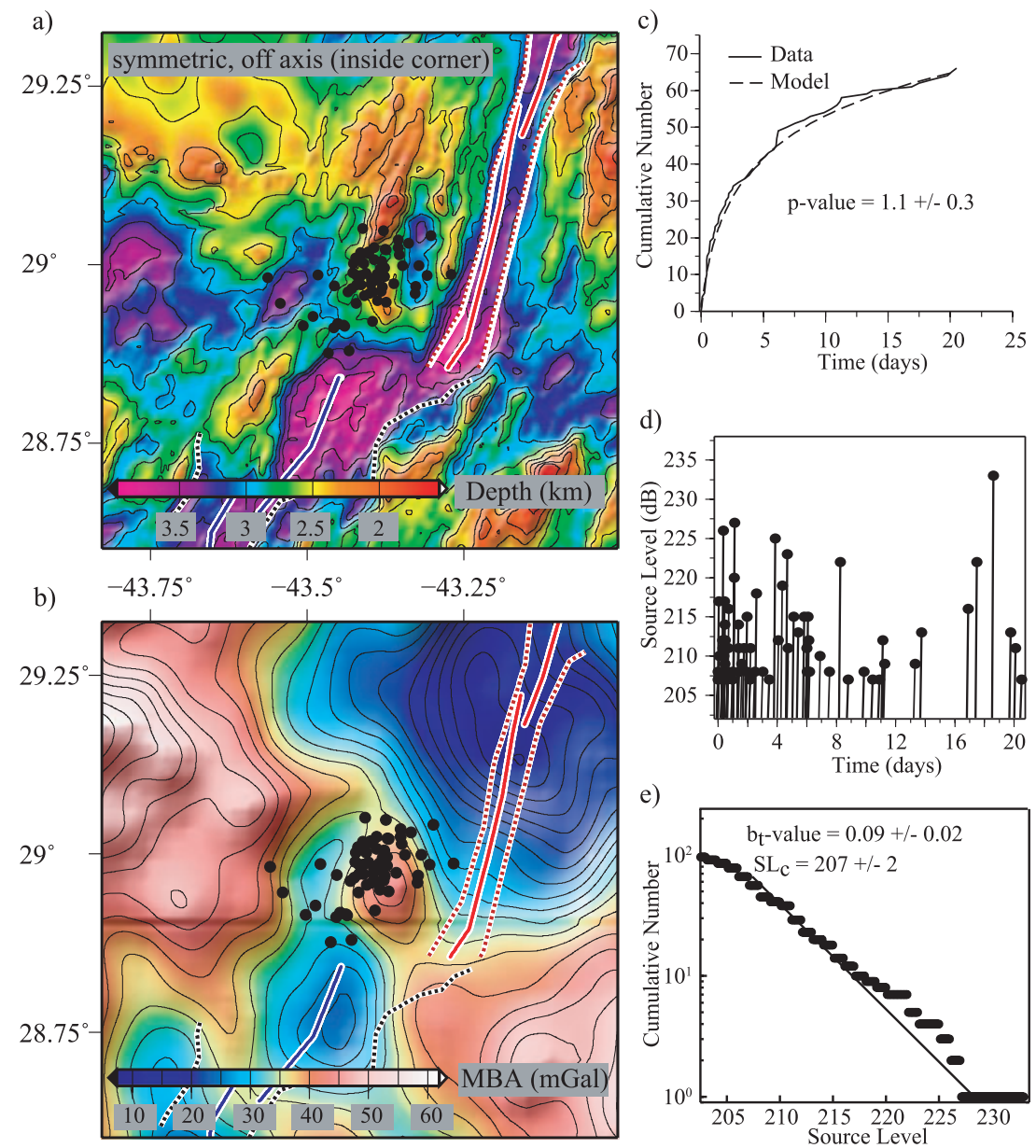

Figure 11. Seismic sequence that started on 2001 February 28.

well below the bathymetry highs of the axial valley walls (Table 1 , Figs 8a, 9a and 10a). This shows that $T$-phase conversion occurs as frequently in the deep seafloor as in shallower regions, indicating there is no significant bias in source locations due to bathymetric variations. It also appears that $S L_{c}$ does not depend on the location of the swarms inside the ridge axial valley, where the propagation path interacts strongly with bathymetry, or within shallower regions where the path of propagation is clearer. Moreover, the fact that 8 sequences were recorded between the Hayes and Kane fracture zones indicates detection of swarm activity is not only related to hydrophone detection threshold for a given region, since the $S L_{c}$ for those sequences are not systematically smaller than the detection threshold of the sequences recorded in other regions. Also the numbers of events in the sequences with a Source Level bigger than the $S L_{c}$ used for the Modified Omori Law fits does not have a clear dependence on the $S L_{c}$ (Table 2). This suggests that the number of events recorded by the AuH for each sequence can be highly influenced by the fault mechanics and/or of the seismic phases to $T$-phase conversion.

It is possible to use $b_{t}$-value analyses of the sequences to provide an idea of the Source Level distribution of earthquakes. If Source Level results mainly from the mechanics of fault failure with only a small dependence on the seismic to acoustic conversion, it would then be possible to observe a dependence of the $b_{t}$-value on the region's rheology (as is the case for the $b$-value). A total of 11 out of the 13 sequences have $b_{t}$-values in between 0.05 and 0.10 . The sequence recorded on 2001 January had a $b_{t}$-value of 0.12 . This sequence occurred very close to the ridge axis on the neovolcanic section of the segment and on a part of the ridge where spreading is considered to be asymmetrical and where detachment faulting is common (Fig. 10). The sequence recorded during 2001 March from the Lucky Strike segment, home to the Lucky Strike volcano and where are indices of the existence of a magma chamber (Singh et al. 2006) also has a large $b_{t}$-value of 0.14 . This sequence was well recorded by land based networks due to a large number of medium to large magnitude earthquakes $(m b>3.5)$. This sequence has been interpreted as a result of intrusive magmatic activity (Dziak et al. 2004a). The fact that the two sequences with the highest $b_{t}$-values were recorded near to what is generally considered neovolcanic sections of the MAR seems to suggest a connection between high frequency-size constants and proximity to lithospheric heat sources has observed by Wyss et al. (2001a,b). This liaison needs to be regarded with caution due to the nature of Source Level and the small number of examples upon which this hypotheses is based.

Generally, events occurring at the beginning of the sequences have higher Source Levels and are directly linked to the mainshock and to stronger events. The three exceptions to this are the 2001 January sequence and the 2001 February sequence, where land based networks did not record any event and the 2001 March sequence where the Source Levels linked to the magnitude of the earthquakes recorded by the land based networks were low. Although the sequence $S L_{c}$ calculated for this zone is relatively high, 

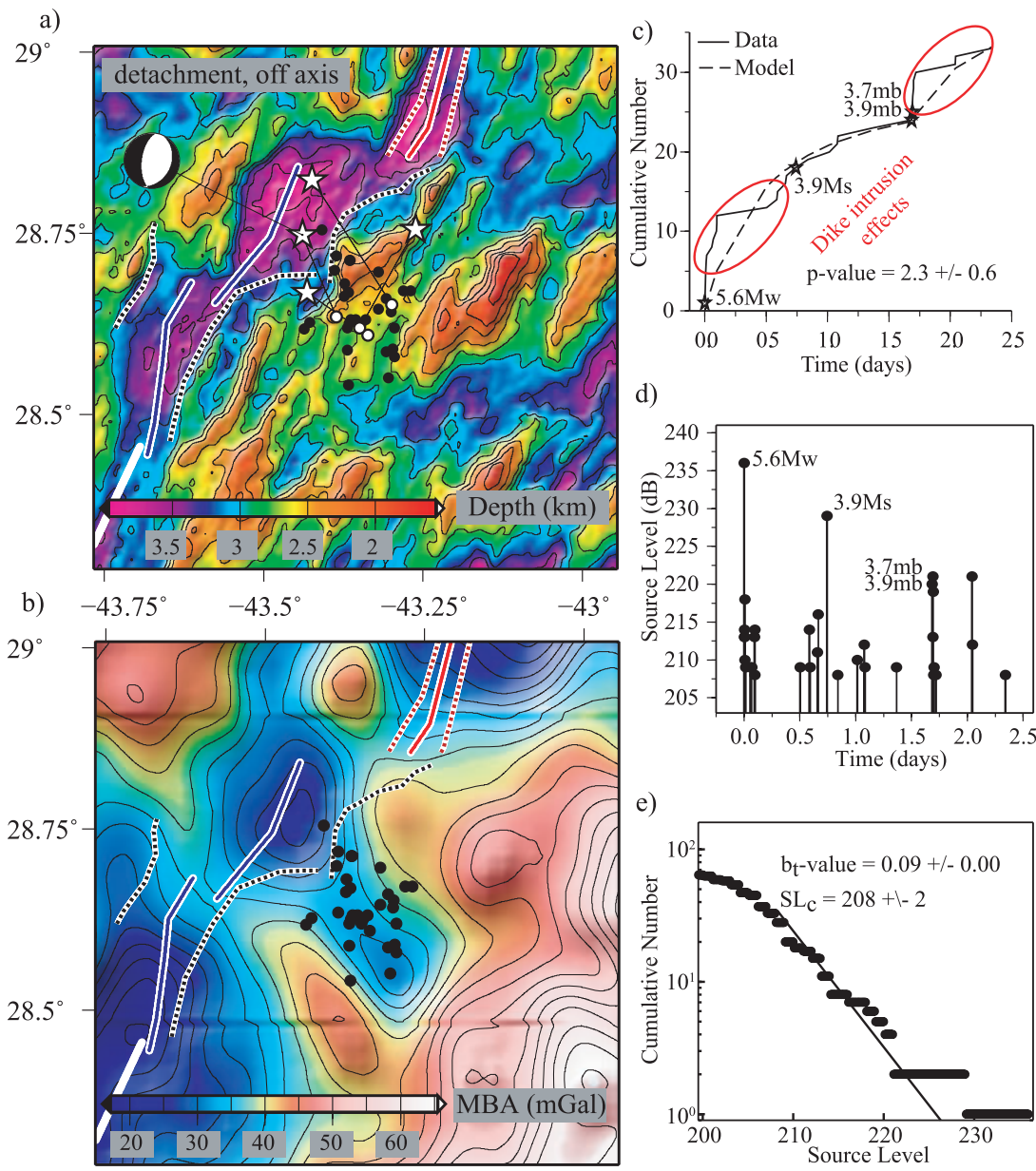

d)

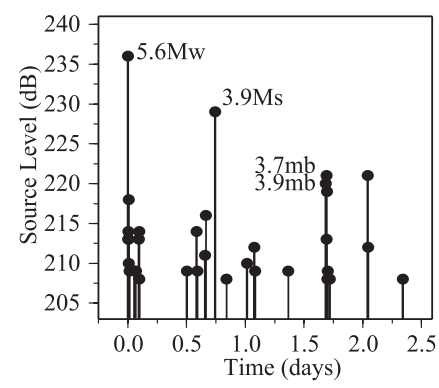

e)

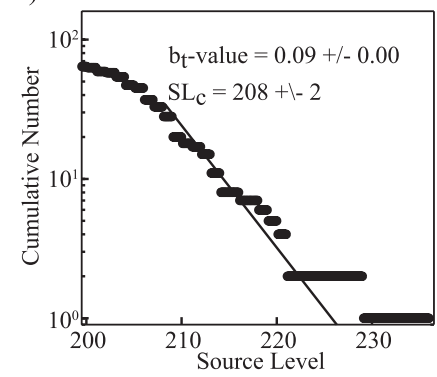

Figure 12. Seismic sequence that started on 2001 July 13.

it is not extreme in comparison with other sequences from other regions (Table 2). This can indicate that there is some kind of $T$-phase conversion or propagation issue for this sequence, perhaps caused by the sequence location on a shallower region on the middle of the Azores Plateau and relatively far from the AuH array that recorded it. This again suggests caution when interpreting the $b_{t}$-value.

From the 13 identified seismic sequences, only eight sequences have a goodness of fit $K S_{\text {stat }}$ values within the 95 per cent confidence level to allow interpretation (Table 3). Table 3 and Figs 4(c), 8(c) and 9(c) show that four seismic sequences have extremely high $p$ values ( $>2$ ) and 7 are of short duration (less than 7 days). Other studies conducted on MAR seismic sequences suggested that large $p$-values can be due to exceptionally high temperatures normally found in the ridge median valley (Bohnenstiehl et al. 2002) and that short duration sequences may involve the migration of hydrothermal fluids that will reduce the strength of fault zones (Goslin et al. 2005).

A recent study identified two distinct modes of accretion along the MAR between the Marathon and Oceanographer Fracture Zones, one involving symmetrical spreading and another asymmetrical spreading associated with detachment faulting (Escartín et al. 2008). Fig. 4(c) shows the distribution of these modes of accretion and the location of the seismic sequences. Out of 10 sequences within this section of the ridge, seven occur in association with detachments (Figs 4c, 8a, 9a, 10a, 12a and 14a) and three with symmetric segments (Figs 4c, 7a, 11a and 13a). In general, sequences in detachments are of shorter duration and have a larger $p$-value (1.4-2.7) than sequences in symmetric segments (1.1-1.7). We note that the off-axis $(30 \mathrm{~km})$ position of the 2004 April sequence, associated with a detachment, may explain its low $p$-value (1.4).

The apparent dependence of $p$-value on type of accretion may be explained by variations in the rheology of faults. Detachment faults are systematically associated with hydrothermal activity (Escartín et al. 2008; McCaig et al. 2007). Associated fault rocks record a long history of fluid-rock interactions, that results in the formation of weak mineral phases (talc, serpentinite, chlorite) that favour localization of deformation over extended periods of time (Boschi et al. 2006; Escartín et al. 2003a; Schroeder \& John 2004). These detachments are also associated with exhumed peridotites that are partially serpentinized, a material that is also weak relative to unaltered rocks (e.g. Escartín et al. 1997, 2001b). These lithospheric components and in particular detachment fault rocks and associated fluid circulation, can significantly reduce the effective strength of faults, effectively promoting a fast strain decay and short duration of earthquake sequences. Low $p$-values along faults within symmetric sections but off axis of the ridge would instead indicate that the faults developing there are stronger and that the decay rate is slower.

These results also suggest that the mainshock-aftershock characteristics are not reflecting overall lithospheric thickness or strength, but that are dominated by fault rheology. There is no apparent correlation between rift valley geometry and $p$-value. Furthermore, 

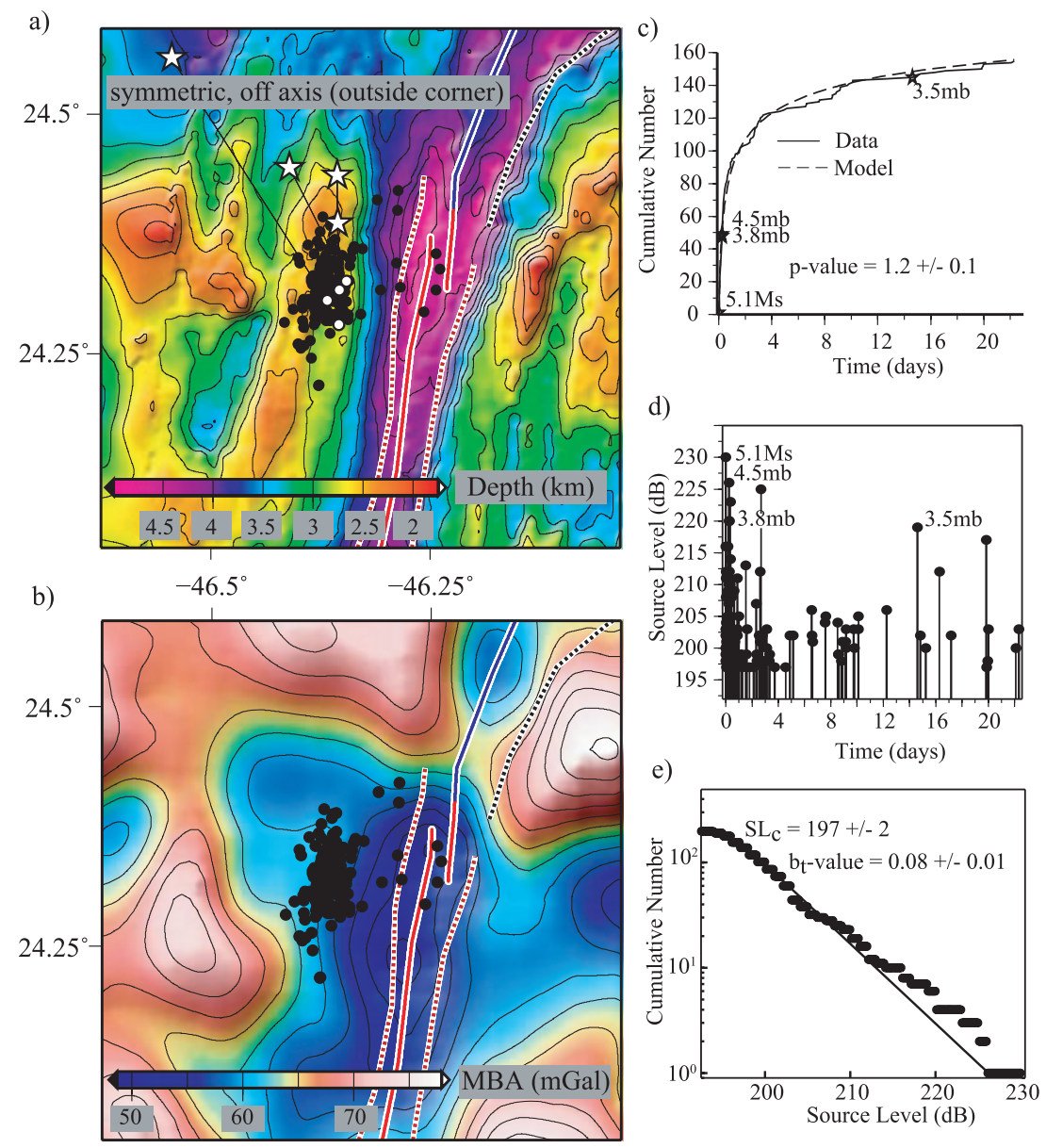

Figure 13. Seismic sequence that started on the 2002 March 24.

Table 1. Seismic sequences locations. From the first to the last column in order. Sequences, mean sequence localizations (Lon and Lat), $T$-phase excitation mean depth, mean earthquake distance to the segment axis, mean axial valley width, mean axial valley depth and finally the sequence's position along the axial valley and its spreading mode.

\begin{tabular}{lcccrccc}
\hline Date & Lon $\left({ }^{\circ} W\right)$ & Lat $\left({ }^{\circ} N\right)$ & $\begin{array}{c}\text { Tdpt } \\
(\mathrm{km})\end{array}$ & $\begin{array}{c}\text { Tdst } \\
(\mathrm{km})\end{array}$ & $\begin{array}{c}\text { Width } \\
(\mathrm{km})\end{array}$ & $\begin{array}{c}\text { Depth } \\
(\mathrm{km})\end{array}$ & $\begin{array}{c}\text { Spreading mode } \\
\text { on/off axis }\end{array}$ \\
\hline $19990406^{a}$ & $46.34 \pm 0.03$ & $24.36 \pm 0.05$ & $2.8 \pm 0.5$ & $13 \pm 3$ & 22 & 1.6 & symmetric, outside corner \\
$20000218^{a}$ & $46.58 \pm 0.06$ & $16.55 \pm 0.09$ & $3.6 \pm 0.4$ & $5.0 \pm 4$ & 22 & 1.4 & detachment, on axis \\
20001005 & $40.85 \pm 0.07$ & $31.61 \pm 0.06$ & $3.1 \pm 0.4$ & $6 \pm 4$ & 17 & 0.7 & detachment, on axis \\
20010112 & $44.67 \pm 0.06$ & $26.45 \pm 0.08$ & $3.4 \pm 0.3$ & $5 \pm 5$ & 22 & 1.1 & detachment, on axis \\
20010228 & $43.40 \pm 0.05$ & $28.98 \pm 0.04$ & $2.7 \pm 0.3$ & $13 \pm 3$ & 12 & 0.6 & symmetric, Inside corner \\
$20010316^{b}$ & $32.29 \pm 0.09$ & $37.38 \pm 0.15$ & $2.3 \pm 0.5$ & $8 \pm 6$ & 24 & 0.7 & $?$, on axis \\
20010713 & $43.34 \pm 0.04$ & $28.64 \pm 0.05$ & $2.6 \pm 0.3$ & $19 \pm 5$ & 26 & 1.1 & detachment, off axis \\
20011112 & $45.50 \pm 0.04$ & $22.22 \pm 0.05$ & $3.8 \pm 0.4$ & $7 \pm 4$ & 21 & 0.8 & detachment, on axis \\
20011213 & $44.31 \pm 0.04$ & $26.90 \pm 0.08$ & $2.8 \pm 0.3$ & $18 \pm 5$ & 18 & 1.0 & detachment, off axis \\
20020324 & $46.36 \pm 0.03$ & $24.32 \pm 0.03$ & $2.8 \pm 0.5$ & $12 \pm 3$ & 22 & 1.6 & symmetric, outside corner \\
20030827 & $28.74 \pm 0.09$ & $43.78 \pm 0.07$ & $2.2 \pm 0.5$ & $13 \pm 4$ & 18 & 0.8 & detachment, inside corner \\
20040416 & $39.36 \pm 0.03$ & $32.83 \pm 0.05$ & $2.0 \pm 0.3$ & $29 \pm 5$ & 16 & 0.8 & detachment, off axis \\
20070213 & $33.94 \pm 0.15$ & $36.09 \pm 0.08$ & $2.0 \pm 0.5$ & $11 \pm 7$ & 16 & 0.7 & ?, on axis \\
\hline
\end{tabular}

Notes. ${ }^{a}$ Sequences garnered from Bohnenstiehl et al. (2002).

${ }^{b}$ Sequence garnered from Dziak et al. (2004a).

sections of the ridge with detachments (such as segment ends) may be associated with a thicker lithosphere than symmetric segments (e.g. Escartín et al. 2008; Shaw 1992). If overall strength (lithospehric thickness) were the main control on the characteristics of earthquake sequences, we would expect that the sequences associated with detachments would show a slow decay rate, instead of the elevated one observed.

\subsection{Magmatic intrusions and transient slip}

Clustered events represent $\sim 55$ per cent of all events recorded by the AuH. The number of events identified in the mainshockaftershock sequences represent less than 10 per cent of these. The criteria used to select the sequences (a minimum of 40 events in the cluster and presence of a mainshock) are of course reductive. 
Table 2. Seismic sequences and size-frequency relationship parameters.

\begin{tabular}{lrcccc}
\hline Date & Events & $\begin{array}{c}S L_{c} \\
(\mathrm{~dB})\end{array}$ & $b_{t}$ & $a_{t}$ & $\begin{array}{c}\text { Events } \\
S L \geq S L_{c}\end{array}$ \\
\hline $19990406^{a}$ & 165 & $211 \pm 2$ & $0.09 \pm 0.02$ & 21 & 66 \\
$20000218^{a}$ & 54 & $210 \pm 5$ & $0.07 \pm 0.02$ & 17 & 31 \\
20001005 & 126 & $206 \pm 1$ & $0.07 \pm 0.00$ & 16 & 49 \\
20010112 & 45 & $206 \pm 1$ & $0.12 \pm 0.05$ & 27 & 29 \\
$20010316^{b}$ & 96 & $210 \pm 2$ & $0.14 \pm 0.00$ & 32 & 66 \\
20010228 & 125 & $207 \pm 2$ & $0.09 \pm 0.02$ & 20 & 52 \\
20010713 & 64 & $208 \pm 2$ & $0.09 \pm 0.00$ & 20 & 33 \\
20011112 & 53 & $202 \pm 1$ & $0.07 \pm 0.01$ & 15 & 44 \\
20011213 & 59 & $203 \pm 1$ & $0.10 \pm 0.02$ & 21 & 36 \\
20020324 & 198 & $197 \pm 2$ & $0.08 \pm 0.01$ & 17 & 155 \\
20030827 & 42 & $212 \pm 4$ & $0.08 \pm 0.05$ & 19 & 22 \\
20040416 & 54 & $210 \pm 2$ & $0.05 \pm 0.00$ & 12 & 33 \\
20070213 & 77 & $200 \pm 2$ & $0.09 \pm 0.02$ & 19 & 55 \\
\hline
\end{tabular}

Notes. ${ }^{a}$ Sequences garnered from Bohnenstiehl et al. (2002).

${ }^{b}$ Sequence garnered from Dziak et al. (2004a).

Nevertheless, the numbers of earthquakes reveal that pure tectonic activity, which are well represented by the Modified Omori Law are just a small minority of the seismic activity recorded on the MAR. Furthermore, five of the identified mainshock-aftershock sequences have poorer fits and where not interpreted. This poorer level of confidence in the Modified Omori Law fits can also be seen as a departure from the tectonic faulting style into more complex regimes.

Fig. 15 shows two of the sections in this part of the MAR, one north of the Azores $\left(43.75^{\circ} \mathrm{N}\right)$ and the other south of the Azores $\left(22^{\circ} \mathrm{N}\right)$. The two sections reveal high number of clustered events. In each of the sections a cluster was found to satisfy the criteria to be included in the analysis of mainshock-aftershock sequences. Both cases revealed Modified Omori Law fits below the 95 per cent confidence level and the respective $p$-value was not interpreted. The rest of the clustered events were too few in numbers or lacked the mainshock to satisfy the criteria. The two different sections show two types of seismic crises observed on the MAR. The first, the mainshock-aftershock sequences without a clear spatial migration of the seismicity. The second, as illustrated in $(i),(j)$ and $(k)$ of Fig. 15(a), reveals variable temporal occurrence rates for the events, which is related to the spatial migration of the earthquakes. The first type was thoroughly discussed in the section above. The second type of clusters with spatial migration of the earthquakes suggests a type of seismic activity caused by dyke intrusion and where the migration follows the propagation of the ruptures caused by the flow of lava (Dziak \& Fox 1999b; Dziak et al. 2004a, 2007). This dyke intrusion magmatic type of activity can also occur jointly with tectonic activity, as is the case with the well fitted sequences recorded in 2000 February and 2001 July (Figs $8 \mathrm{c}$ and 12c) or with the sequence recorded in 2003 August (Fig. 15b) where the $p$-value analysis was undermine. The rates of earthquake occurrence in dyke intrusions vary from cluster to cluster. The rates of dyke propagation are related to the level of excess magma pressure at the dyke source, which results from a new influx of melt from the mantle (Jaupart \& Tait 1995; Rubin 1995). This will influence the occurrence rate of of earthquakes that will accompany the propagating cracking. The regional crustal stress state and changes due to active faulting may also play a role in dictating the occurrence of dyke intrusions and the distance that they can propagate. A more brittle lithosphere may make it easier for the dyke to initiate and propagate (Dziak et al. 2007).

The departures from the Modified Omori Law could also be due to the connection between the detachment faults with the hydrothermal circulation and that weak and very altered rocks can promote the existence of aseismic transient slip, diminishing the rate of earthquakes expected by the Modified Omori Law (Figs 8c, 9c and $10 \mathrm{c}$ ), thereby adding more complexity to the normal process of tectonic rupture. This was widely observed on the oceanic seafloor near coastal regions using GPS stations situated nearby thrust faults on subduction areas (Cho et al. 2009; Liu et al. 2007; McGuire \& Segall 2003). Also following on from the work of McGuire et al. (2005), Figs 8(c) and 9(c) show that those sequences present foreshocks before the mainshock, with some of them even observed teleseismically and through no coincidence the $p$-value obtained for these sequences are the greatest. In comparison to McGuire et al. (2005) the presence of foreshocks on mid oceanic ridges were not observed in the fracture zones as for the EPR but on segments of the MAR. The author inferred that large earthquakes on EPR transform faults are preceded by an extended preparation process, possibly driven by sub-seismic transients, that can often be observed through foreshocks and that physically link to the mainshock-aftershock sequence through stress changes driven by the aseismic slip or some

Table 3. Seismic sequences Modified Omori Law fitting parameters. Values in parenthesis (if any) are the Modified Omori Law parameters associated to the secondary mainshock.

\begin{tabular}{llrcccrc}
\hline Date & \multicolumn{1}{c}{$\begin{array}{c}T_{\min }(\mathrm{sec}) \\
\text { (days) }\end{array}$} & $\begin{array}{r}T_{\max } \\
\text { (days) }\end{array}$ & \multicolumn{1}{c}{$\mathrm{p}_{1}\left(\mathrm{p}_{2}\right)$} & $\mathrm{c}_{1}\left(\mathrm{c}_{2}\right)$ & $\mathrm{K}_{1}\left(\mathrm{~K}_{2}\right)$ & AIC & $\mathrm{KS}_{\text {stat }}(95$ per cent $)$ \\
\hline $19990406^{a}$ & $0.001(-)$ & 11.890 & $1.7 \pm 0.3(-)$ & $0.24 \pm 0.15(-)$ & $18 \pm 7(-)$ & -288 & $0.108(0.164)$ \\
$20000218^{a}$ & $0.019(3.946)$ & 6.733 & $2.7 \pm 0.1(-)$ & $1.51 \pm 0.28(-)$ & $79 \pm 20(18 \pm 10)$ & -37 & $0.182(0.238)$ \\
20001005 & $0.003(-)$ & 1.762 & $2.6 \pm 0.5(-)$ & $0.30 \pm 0.10(-)$ & $10 \pm 4(-)$ & -236 & $0.189(0.190)$ \\
20010112 & $0.021(-)$ & 3.837 & $2.7 \pm 0.4(-)$ & $0.38 \pm 0.15(-)$ & $10 \pm 9(-)$ & -98 & $0.125(0.246)$ \\
20010228 & $0.005(-)$ & 20.503 & $1.1 \pm 0.3(-)$ & $0.67 \pm 0.78(-)$ & $20 \pm 15(-)$ & -80 & $0.062(0.164)$ \\
$20010316^{b, c}$ & $0.001(-)$ & 1.214 & $0.9 \pm 0.8(-)$ & $0.01 \pm 0.46(-)$ & $10 \pm 21(-)$ & -161 & $0.129(0.238)$ \\
20010713 & $0.003(1.690)$ & 2.431 & $2.3 \pm 0.6(-)$ & $1.15 \pm 0.59(-)$ & $48 \pm 27(49 \pm 23)$ & -112 & $0.188(0.231)$ \\
$20011112^{b}$ & $0.002(-)$ & 2.793 & $2.7 \pm 0.4(-)$ & $0.32 \pm 0.06(-)$ & $10 \pm 2(-)$ & -202 & $0.242(0.201)$ \\
$20011213^{b}$ & $0.001(-)$ & 1.785 & $0.8 \pm 0.6(-)$ & $0.01 \pm 0.37(-)$ & $10 \pm 14(-)$ & -167 & $0.286(0.227)$ \\
20020324 & $0.003(-)$ & 22.319 & $1.2 \pm 0.1(-)$ & $0.05 \pm 0.04(-)$ & $25 \pm 4(-)$ & -749 & $0.058(0.109)$ \\
$20030827^{b}$ & $0.002(-)$ & 17.584 & $1.5 \pm 0.3(-)$ & $0.51 \pm 0.70(-)$ & $10 \pm 9(-)$ & 9 & $0.350(0.281)$ \\
20040416 & $0.001(-)$ & 12.776 & $1.4 \pm 0.4(-)$ & $0.24 \pm 0.33(-)$ & $10 \pm 15(-)$ & -35 & $0.125(0.231)$ \\
$20070213^{b}$ & $0.040(-)$ & 4.898 & $0.8 \pm 0.6(-)$ & $0.01 \pm 0.51(-)$ & $11 \pm 19(-)$ & -133 & $0.278(0.180)$ \\
\hline
\end{tabular}

Notes. ${ }^{a}$ Sequences garnered from Bohnenstiehl et al. (2002).

${ }^{b}$ Sequences where the $p$-value was not interpreted ( $\mathrm{KS}_{\text {stat }}$ greater than the tabled value for the 95 per cent confidence level).

${ }^{c}$ Sequence garnered from Dziak et al. (2004a). 

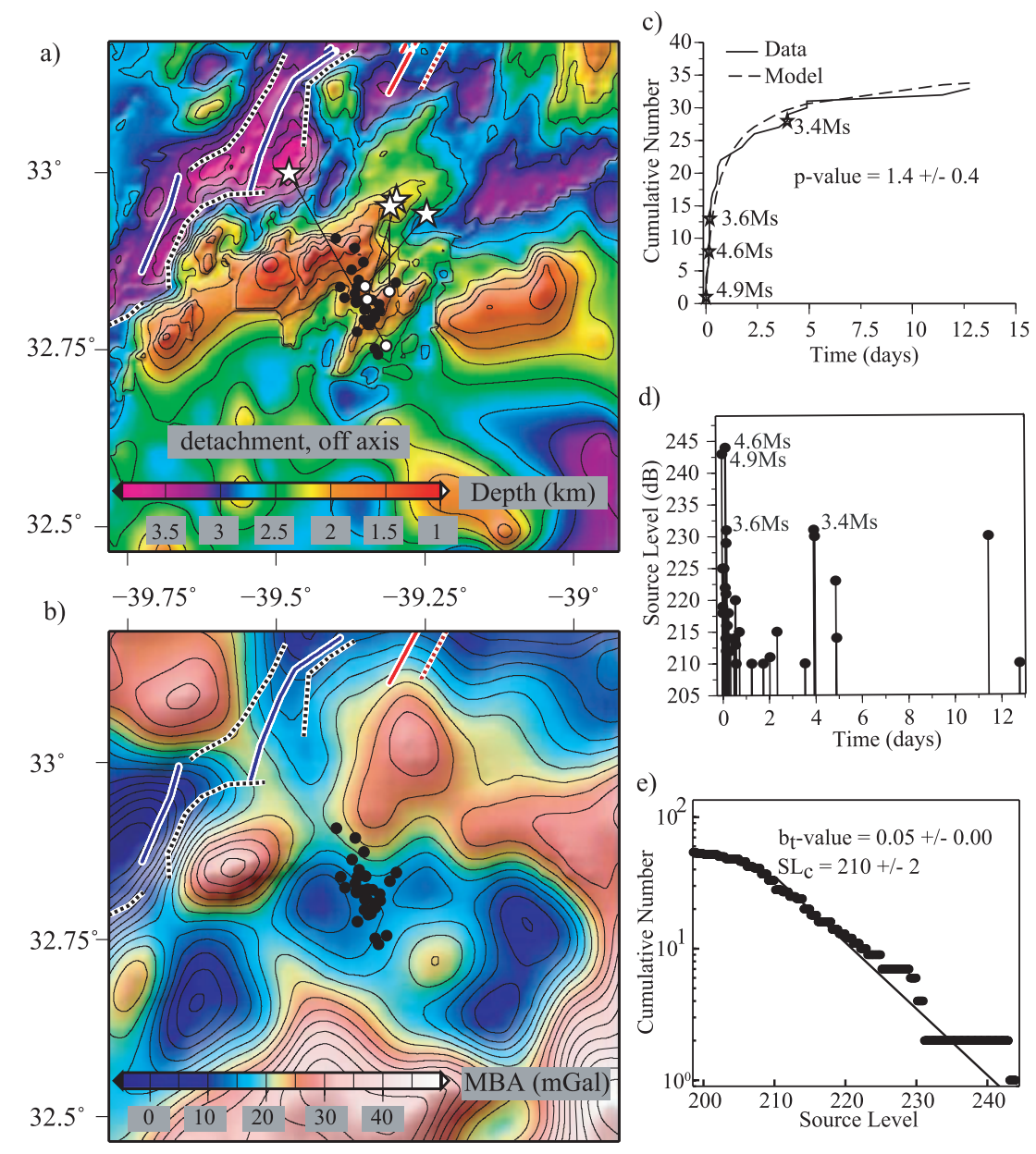

Figure 14. Seismic sequence that started on 2004 April 16.

other fault preparation process such as hydrothermal flow or nearby magmatic activity.

All this complexity in the rheology of slow oceanic ridges, that is also interconnected with the close relationship between tectonic and magmatic activity in the formation of faulting and axial morphology (Behn \& Ito 2008; Ito \& Behn 2008), suggests that seismic activity in these conditions is very rarely purely tectonic or purely volcanic. That said it is still clear to state that dyke intrusion activity is the major cause for the clustered earthquake activity in the MAR and represents nearly half of the total seismic activity.

\section{CONCLUSIONS}

The major advantage of AuH recorded earthquakes, in comparison with teleseismically recorded earthquakes, is the lower detection threshold that $\mathrm{AuH}$ arrays can provide. A size frequency analysis of the AuH catalogues deployed in the MAR revealed that the Source Level of Completeness can vary in a range of $15 d B$ in a region of the MAR delimited by the Marathon and Charles-Gibbs Fracture zones. A region spanning more than $5000 \mathrm{~km}$. This difference in $S L_{c}$ can have a dramatic influence on the numbers of recorded earthquakes. This seems to be particularly true in the region between the Oceanographer Fracture Zone and the Azores, where, for the period up until 2005 there was a deficiency in the number of earthquakes recorded. This deficiency was no longer observed for the period between 2005 and 2007.
The visual inspection and correlation analysis of broad wavelength profiles of MAR's seismicity reveal a strong correlation between declustered catalogues of the $\mathrm{AuH}$ recorded seismicity and the teleseismically recorded seismicity. This shows that temporally limited seismic monitoring experiments on the MAR can reveal the same background seismicity patterns observed on the long term 40 year data set of teleseismic observations. The joint analysis of the long wavelengths of the $\mathrm{AuH}$ and ISC seismicity distributions reveals low levels of seismicity for a distance as far as $200 \mathrm{~km}$ from the Azores that can be linked to the influence of the hotspot.

The cluster analysis of the seismicity on the MAR was carried out with the objective of adding further data to existing work on cluster analysis and of emphasizing seismic sequence analysis, using Modified Omori Law and frequency-size principles, to better constrain the modes of faulting and the detection threshold issues from different regions of the MAR. Seismic sequences occur on segments with well developed axial valleys reenforcing the idea that these segments are in a relatively cold thermal state. Seismic sequences can be detected inside the axial valley or on the flanks up to distances as great as $30 \mathrm{~km}$ off axis.

Frequency-size analysis suggests caution when interpreting $b_{t}$-values due to the $T$-phase based earthquake energy source level dependence on the conversion of the seismic waves into acoustic waves and on the interaction of the propagating acoustic phase with the surrounding bathymetry. This dependence is not restrictive though, because as shown, the number of events detected for each sequence does not depend entirely on the detection threshold $S L_{c}$ 

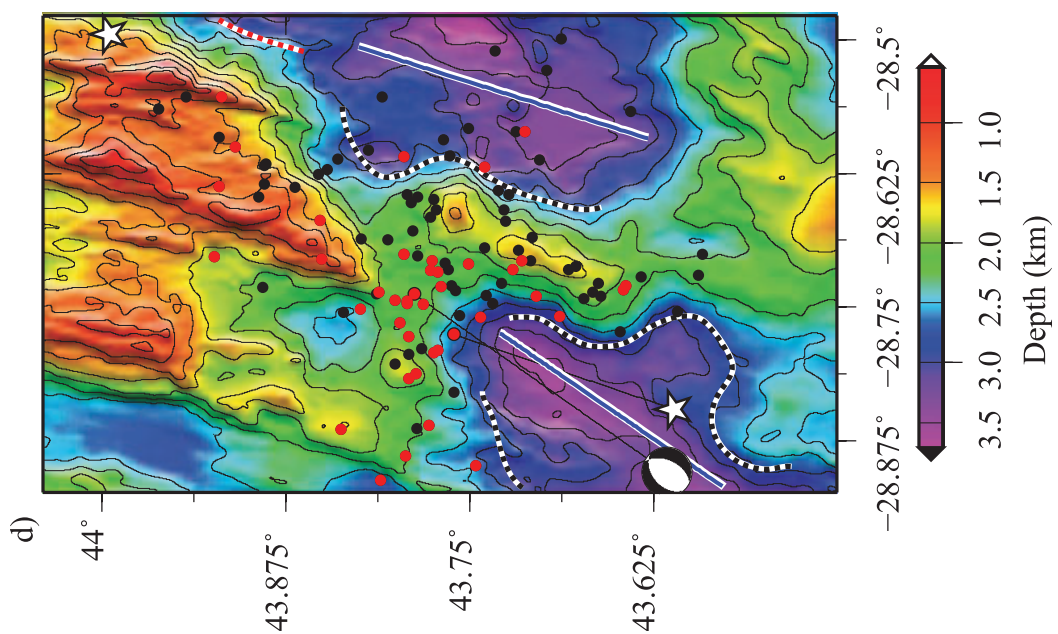

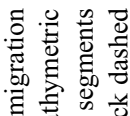

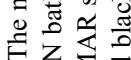

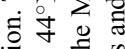

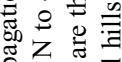

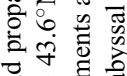

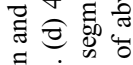

总造起

总通自

宫喜爱

of

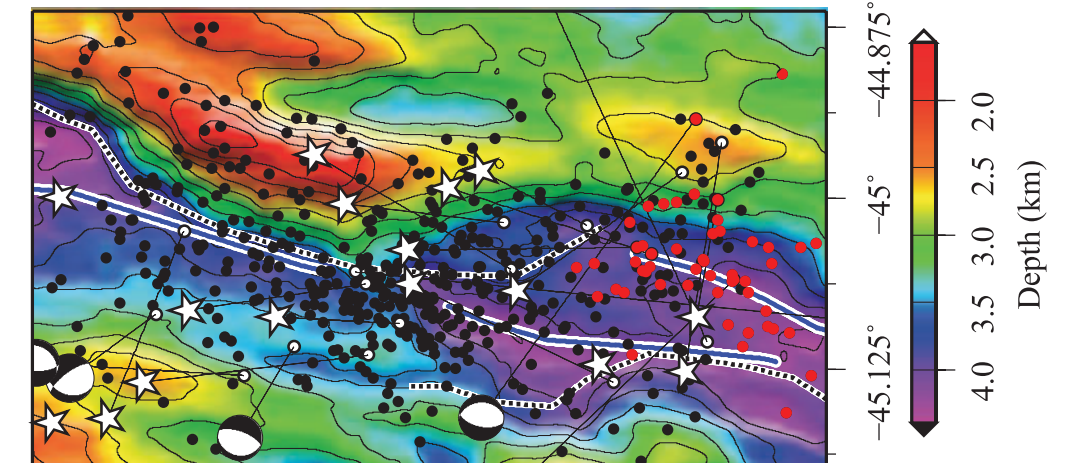

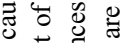



Z.:

氜 品

这 语

苋范

敋高

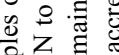

출

他 若

过苔

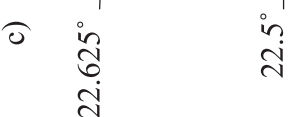

in $\stackrel{i}{i}$ ì

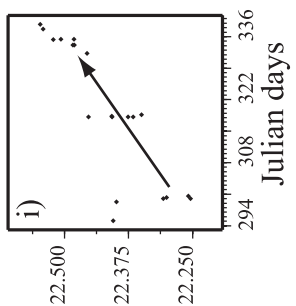

әрпџฺт Т
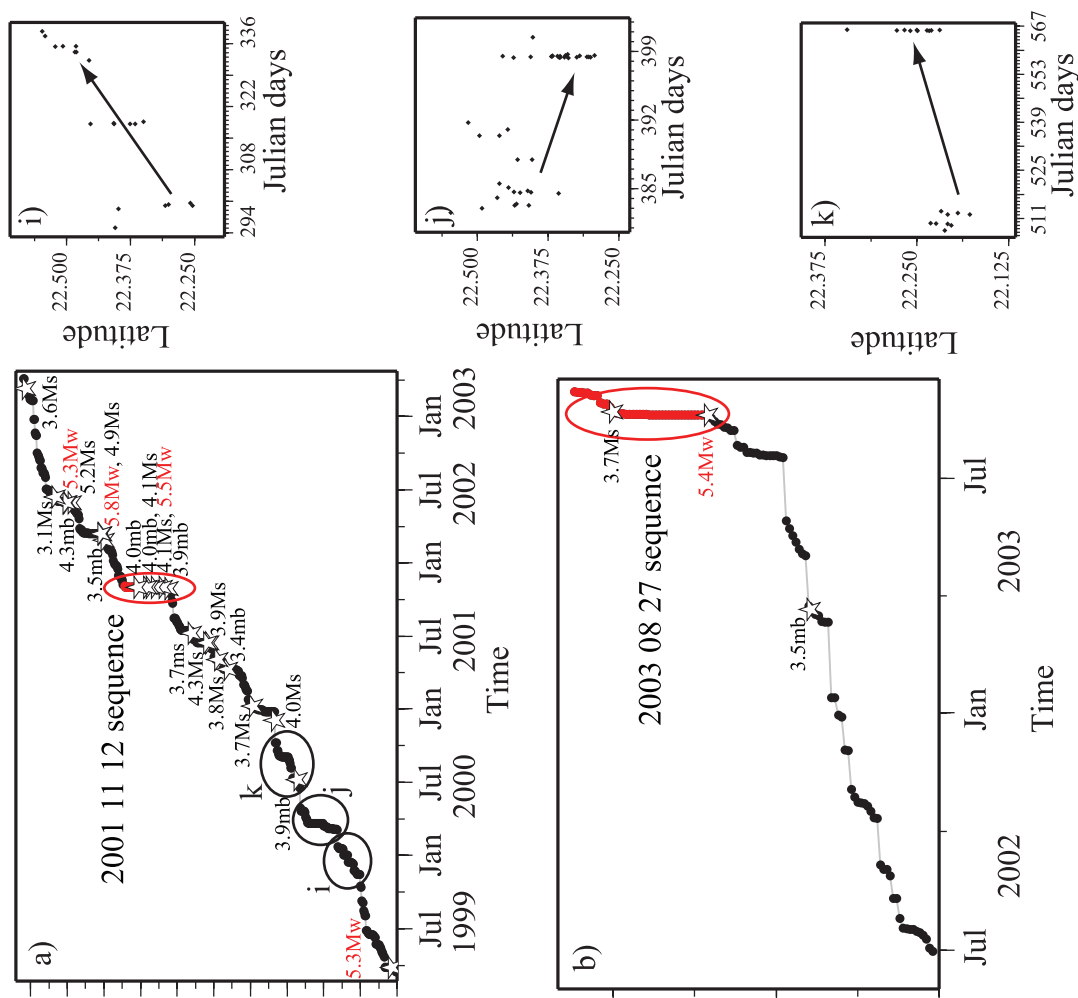

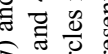

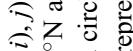

$z$ 要

i.

ते एँ

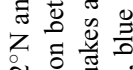

สิ

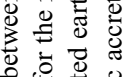

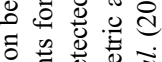

कृ

Ð す

氙苛

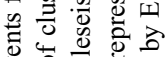

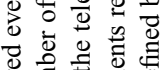

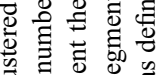

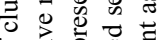

突婄㤩

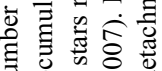

范

音言宁范

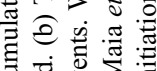

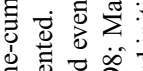

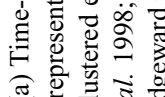

$\approx$ ब 5

เ

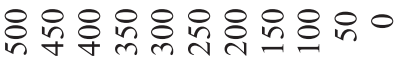

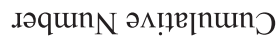

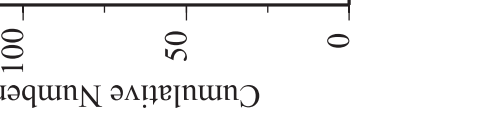

Wh 


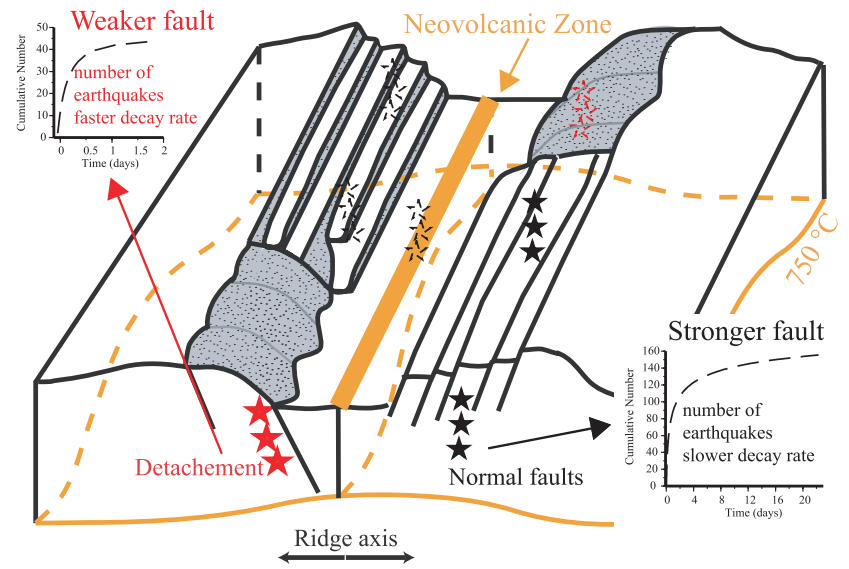

Figure 16. Sketch of the generic modes of faulting on one composite MAR segment and their relation to fault strength and decay rate of earthquake sequences. Detachment faults associated with an asymmetrical mode of spreading have a faster decay rate. Abyssal hill faulting associated with an symmetrical mode of spreading have a slower decay rate of earthquakes. Stars represent seismic sequences. Sketch modified and adapted from Shaw (1992).

and can be representative of the faulting mechanisms. This permits $T$-phase detected earthquake mainshock-aftershock sequences to be used on number rate decay with Modified Omori Law analysis.

The locations of the sequences were also analysed regarding the segmentation and the MBA of the MAR. All the sequences are associated with higher MBA areas of the segments, suggesting that seismic sequences are more prone to occur in regions of the MAR with a more brittle and thinner type of crust. The crust thermal regime does not seem to be the major influence in the earthquake decay rate and the rheological strength of the fault region. The resulting $p$-values seems to be more dependent on the type of faulting occurring in the region and seems to suggest that high anomaly $p$-values are generally associated with detachment faulting created by asymmetric accretion on the MAR and that smaller $p$-values are associated with a normal abyssal hill type of faulting associated with more symmetric type of accretion (Fig. 16). This dependence seems to be determined primarily by the weak rheology of detachment faults relative to those found along symmetric, more magmatic segments, as they contain weak mineral phases and may be associated with hydrothermal fluids that weaken them and promote strain release and a fast decay.

Nearly half of the MAR seismicity seems to be related to dyke intrusion and propagation along the ridge. This type of rupture mechanism most likely interacts strongly with the more traditional types of faulting. This will be reflected in the goodness of fit obtained for the Modified Omori Law analysis of the mainshockaftershock sequences. Poorer Modified Omori Law goodness of fit of the sequences can also be explained by periods of transient slip along the sequence. The aseismic transient slip may possibly be having an effect on both the duration and $p$-values of the fitted mainshock-aftershock sequences. The existence of an aseismic transient slip on the MAR is further justified by other studies which revealed/explored the connection between its presence and the number of foreshocks in the mainshock-aftershock sequences recorded on mid-oceanic ridges.

\section{ACKNOWLEDGMENTS}

This work was made possible by the EU FP6 Marie Curie RTN MoMARnet, Université de Brest - Institut Universitaire Européen de la Mer, CNRS/INSU, Oregon State University, NOAA/PMEL and the country of Portugal. This paper is IPGP contribution number 3080 and PMEL contribution number 3618. The AuH operations were carried out by Cédric Brachet, Matt Fowler and Joe Haxel. A special word to Haruyoshi Matsumoto, designer of the $\mathrm{AuH}$ and Tai-Kwan Lau, programmer of the $T$-phase analysis software. Crews and captains of several research vessels from France, Portugal, United Kingdom and USA helped us to make this project a success. Moreover, this manuscript profited greatly from discussions with Carole Cordier, Del-Wayne Bohnenstiehl, Nicolas ChamotRooke, Joaquim Luis, Marcia Maia, Jean-Yves Royer and Deborah Smith. We thank one anonymous reviewer and Maya Tolstoy, who helped us improve this manuscript. The Generic Mapping Tools was heavily used in the making of the Figs for this paper. Last but not least I would like to thank the Laboratoire de Géologie de L'École Normale Supérieure for its support on the preparation of this manuscript.

\section{REFERENCES}

Akaike, H., 1973. Maximum likelihood identification of Gaussian autoregressive moving average models, Biometrika, 60(2), 255-265.

Behn, M.D. \& Ito, G., 2008. Magmatic and tectonic extension at mid-ocean ridges: 1. Controls on fault characteristics, Geochem. Geophys. Geosyst., 9(8), Q08O10, doi:10.1029/2008GC001965.

Bevington, P. \& Robinson, K.D., 2003. Data Reduction and Error Analysis for the Physical Sciences, 3rd edn, McGraw-Hill, New York.

Blackman, D.K. et al., 2002. Geology of the Atlantis massif (Mid-Atlantic Ridge, $30^{\circ} \mathrm{N}$ ): implications for the evolution of an ultramafic oceanic core complex, Mar. Geophys. Res., 23(5/6), 443-469.

Bohnenstiehl, D.R. \& Tolstoy, M., 2003. Comparison of teleseismic- and hydroacoustic-derived earthquake locations along the north-central MidAtlantic Ridge and equatorial East-Pacific Rise, Seismol. Res. Lett., 74(6), 790-801.

Bohnenstiehl, D.R., Tolstoy, M., Dziak, R.P., Fox, C.G. \& Smith, D.K., 2002. Aftershock sequences in the mid-ocean ridge environment: an analysis using hydroacoustic data, Tectonophysics, 354, 49-70.

Bohnenstiehl, D.R., Tolstoy, M., Smith, D.K., Fox, C.G. \& Dziak, R.P., 2003. Time-clustering behavior of spreading-center seismicity between $15^{\circ} \mathrm{N}$ and $35^{\circ} \mathrm{N}$ on the Mid-Atlantic Ridge: observations from hydroacoustic monitoring, Phys. Earth planet. Int., 138, 147-161.

Boschi, C., Früh-Green, G.L., Delacour, A., Karson, J.A. \& Kelley, D.S., 2006. Mass transfer and fluid flow during detachment faulting and development of an oceanic core complex, Atlantis massif (MAR 30 N), Geochem. Geophys. Geosyst., 7(1), Q01004, doi:10.1029/2005GC001704.

Cannat, M. et al., 1999. Mid-Atlantic Ridge-Azores hotspot interactions: along-axis migration of a hotspot-derived event of enhanced magmatism 10 to 4 Ma ago, Earth planet. Sci. Lett., 173(3), 257-269.

Cho, I., Tada, T. \& Kuwahara, Y., 2009. Stress triggering of large earthquakes complicated by transient aseismic slip episodes, J. geophys. Res., 114(B7), B07310, doi:10.1029/2008JB006125.

Davis, S.D. \& Frohlich, C., 1991a. Single-link cluster analysis, synthetic earthquake catalogues, and aftershock identification, Geophys. J. Int., 104(2), 289-306.

Davis, S.D. \& Frohlich, C., 1991b. Single-Link cluster analysis of earthquake aftershocks: decay laws and regional variations, J. geophys. Res., 96(B4), 6335-6350.

deMartin, B.J., Sohn, R.A., Canales, J.P. \& Humphris, S.E., 2007. Kinematics and geometry of active detachment faulting beneath the Trans-Atlantic Geotraverse (TAG) hydrothermal field on the Mid-Atlantic Ridge, Geology, 35(8), 711-714.

Desbruyères, D. et al., 2001. Variations in deep-sea hydrothermal vent communities on the Mid-Atlantic Ridge near the Azores plateau. Deep Sea Research Part I: Oceanographic Research Papers, 48(5), 13251346. 
Detrick, R.S., Needham, H.D. \& Renard, V., 1995. Gravity anomalies and crustal thickness variations along the Mid-Atlantic Ridge between $33^{\circ} \mathrm{N}$ and $40^{\circ} \mathrm{N}$, J. geophys. Res., 100(B3), 3767-3787.

Dick, H.J.B., Tivey, M.A. \& Tucholke, B.E., 2008. Plutonic foundation of a slow-spreading ridge segment: oceanic core complex at Kane megamullion, $23^{\circ} 30 \mathrm{~N} 45^{\circ} 20 \mathrm{~W}$, Geochem. Geophys. Geosyst., 9(5), Q05014, doi:10.1029/2007GC001645.

Dieterich, J., 1994. A constitutive law for rate of earthquake production and its application to earthquake clustering, J. geophys. Res., 99(B9), 2601-2618.

Dziak, R., Bohnenstiehl, D., Cowen, J., Baker, E., Rubin, K., Haxel, J. \& Fowler, M., 2007. Rapid dike emplacement leads to eruptions and hydrothermal plume release during seafloor spreading events, Geology, 35(7), 579-582.

Dziak, R.P., 2001. Empirical relationship of T-wave energy and fault parameters of northeast Pacific Ocean earthquakes, Geophys. Res. Lett., 28(13), 2537-2540.

Dziak, R.P. \& Fox, C.G., 1999b. The January 1998 earthquake swarm at Axial Volcano, Juan de Fuca Ridge: hydroacoustic evidence of a seafloor volcanic activity., Geophys. Res. Lett., 26(23), 3429-3432.

Dziak, R.P., Smith, D.K., Bohnenstiehl, D.R., Fox, C.G., Desbruyeres, D., Matsumoto, H., Tolstoy, M. \& Fornari, D.J., 2004a. Evidence of a recent magma dike intrusion at the slow spreading Lucky Strike segment, Mid-Atlantic Ridge, J. geophys. Res., 109(B12102), doi:10.1029/2004JB003141.

Dziak, R.P. et al., 2004b. P- and T-wave detection thresholds, Pn velocity estimate, and detection of lower mantle and core P-waves on ocean soundchannel hydrophones at the Mid-Atlantic Ridge, Bull. seism. Soc. Am., 94(2), 665-677.

Escartín, J., Hirth, G. \& Evans, B., 1997. Effects of serpentinization on the lithospheric strength and the style of normal faulting at slow-spreading ridges, Earth planet. Sci. Lett., 151, 181-189.

Escartín, J., Cannat, M., Pouliquen, G., Rabain, A. \& Lin, J., 2001a. Crustal thickness of V-shaped ridges south of the Azores: Interaction of the MidAtlantic Ridge $\left(36^{\circ}-39^{\circ} \mathrm{N}\right)$ and the Azores hot spot, J. geophys. Res., 106(B10), 21 719-21 735.

Escartín, J., Hirth, G. \& Evans, B., 2001b. Strength of slightly serpentinized peridotites: implications for the tectonics of oceanic lithosphere, Geology, 29(11), 1023-1026.

Escartín, J., Mével, C., MacLeod, C.J. \& McCaig, A.M., 2003a. Constraints on deformation conditions and the origin of oceanic detachments: the Mid-Atlantic Ridge core complex at $15^{\circ} 45^{\prime} \mathrm{N}$, Geochemistry Geophysics Geosystems, 4(8), 1067, doi:10.1029/2002GC000472.

Escartín, J., Smith, D.K. \& Cannat, M., 2003b. Parallel bands of seismicity at the Mid-Atlantic Ridge, $12-14^{\circ}$ N, Geophys. Res. Lett., 30(12), 1620, doi:10.1029/2003GL017226.

Escartín, J., Smith, D.K., Cann, J., Schouten, H., Langmuir, C.H. \& Escrig, S., 2008. Central role of detachment faults in accretion of slow-spreading oceanic lithosphere, Nature, 455(7214), 790-794.

Fox, C.G., Matsumoto, H. \& Tai-Kwan, A.L., 2001. Monitoring Pacific Ocean seismicity from an autonomous hydrophone array, J. geophys. Res., 106(B3), 4183-4206.

Frohlich, C. \& Davis, S.D., 1990. Single-link cluster analysis as a method to evaluate spatial and temporal properties of earthquake catalogues, Geophys. J. Int., 100(1), 19-32.

Gente, P., Mével, C., Auzende, J., Karson, J. \& Fouquet, Y., 1991. An example of a recent accretion on the Mid-Atlantic Ridge: the Snake Pit neovolcanic ridge (MARK area, $23^{\circ} 22^{\prime} \mathrm{N}$ ), Tectonophysics, 190(1), $1-29$.

Gente, P. et al., 1995. Characteristics and evolution of the segmentation of the Mid-Atlantic Ridge between $20^{\circ} \mathrm{N}$ and $24^{\circ} \mathrm{N}$ during the last 10 million years, Earth planet. Sci. Lett., 129(1-4), 55-71.

Gente, P., Dyment, J., Maia, M. \& Goslin, J., 2003. Interaction between the Mid-Atlantic Ridge and the Azores hot-spot during the last $85 \mathrm{Myr}$ : emplacement and rifting of the hot-spot-derived plateaus, Geochem. Geophys. Geosyst., 4(10), 8514, doi:10.1029/2003GC000527.

Goslin, J. et al., 1999. Extent of Azores plume influence on the Mid-Atlantic Ridge north of the hotspot, Geology, 27(11), 991-994.
Goslin, J., Lourenço, N., Dziak, R.P., Bohnenstiehl, D.R., Haxel, J. \& Luis, J., 2005. Long-term seismicity of the Reykjanes Ridge (North Atlantic) recorded by a regional hydrophone array, Geophys. J. Int., 162, 516-524.

Gutenberg, B. \& Richter, C.F., 1944. Frequency of earthquakes in California, Bull. seism. Soc. Am., 34(4), 185-188.

Haxel, J.H. \& Dziak, R.P., 2005. Evidence of explosive seafloor volcanic activity from the Walvis Ridge, South Atlantic Ocean, Geophys. Res. Lett., 32, L13609, doi:10.1029/2005GL023205.

Hooft, E.E.E., Detrick, R.S., Toomey, D.R., Collins, J.A. \& Lin, J., 2000. Crustal thickness and structure along three contrasting spreading segments of the Mid-Atlantic Ridge, $33.5^{\circ}-35^{\circ} \mathrm{N}$, J. geophys. Res., 105(B4), $8205-8226$.

Humphris, S.E., Fornari, D.J., Scheirer, D.S., German, C.R. \& Parson, L.M., 2002. Geotectonic setting of hydrothermal activity on the summit of Lucky Strike seamount ( $37^{\circ} 17 \mathrm{~N}$ Mid-Atlantic Ridge), Geochem. Geophys. Geosyst., 3(8), 1049, doi:10.1029/2001GC000284.

International Seismological Centre, 2007. On-line Bulletin. Available at: http://www.isc.ac.uk, Int. Seis. Cent., Thatcham, UK.

Ito, G. \& Behn, M.D., 2008. Magmatic and tectonic extension at mid-ocean ridges: 2. Origin of axial morphology, Geochem. Geophys. Geosyst., 9, Q09O12, doi:10.1029/2008GC001970.

Jaupart, C. \& Tait, S., 1995. Dynamics of differentiation in magma reservoirs, J. geophys. Res., 100(B9), 17 615-17636.

Kagan, Y.Y., 2002. Seismic moment distribution revisited: I. Statistical results, Geophys. J. Int., 148(3), 520-541.

Kelley, D.S. et al., 2005. A serpentinite-hosted ecosystem: the Lost City hydrothermal field, Science, 307(5714), 1428-1434.

Kisslinger, C., 1996. Aftershocks and fault-zone properties, Adv. geophys., 38, 1-36.

Klein, F.W., Wright, T. \& Nakata, J., 2006. Aftershock decay, productivity, and stress rates in Hawaii: indicators of temperature and stress from magma sources, J. geophys. Res., 111(B7), B07307, doi: 10.1029/2005JB003949.

Lin, J., Purdy, G.M., Schouten, H., Sempéré, J.-C. \& Zervas, C., 1990. Evidence from gravity data for focused magmatic accretion along the Mid-Atlantic Ridge, Nature, 344, 627-632.

Liu, Y., Rice, J.R. \& Larson, K.M., 2007. Seismicity variations associated with aseismic transients in Guerrero, Mexico, 1995-2006, Earth planet. Sci. Lett., 262(3-4), 493-504.

Luis, F.J., Miranda, J.M., Galdeano, A., Patriat, P., Rossignol, J.C. \& Mendes Victor, L.A., 1994. The Açores Triple Junction evolution since $10 \mathrm{Ma}$ from an aeromagnetic survey of the Mid-Atlantic Ridge, Earth planet Sci. Lett., 125, 439-459.

Maia, M., Goslin, J. \& Gente, P., 2007. Evolution of the accretion processes along the Mid-Atlantic Ridge north of the Azores since 5.5 Ma: an insight into the interactions between the ridge and the plume, Geochem. Geophys. Geosyst., 8(3), Q03013, doi:10.1029/2006GC001318.

Marsaglia, G., Tsang, W.W. \& Wang, J., 2003. Evaluating Kolmogorov's distribution, Journal of Statistical Software, 8(18), 1-4.

McCaig, A.M., Cliff, R.A., Escartín, J., Fallick, A.E. \& MacLeod, C.J., 2007. Oceanic detachment faults focus very large volumes of black smoker fluids, Geology, 35(10), 935-938.

McGuire, J.J. \& Segall, P., 2003. Imaging of aseismic fault slip transients recorded by dense geodetic networks, Geophys. J. Int., 155(3), 778-788.

McGuire, J.J., Boettcher, M.S. \& Jordan, T.H., 2005. Foreshock sequences and short-term earthquake predictability on East Pacific Rise transform faults, Nature, 434(7032), 457-461.

Miller, L.H., 1956. Table of percentage points of Kolmogorov Statistics, J. Am. Stat. Assoc., 51(273), 111-121.

Nyffenegger, P. \& Frohlich, C., 1998. Recommendations for determining p-values for aftershock sequences and catalogs, Bull. seism. Soc. Am. 88(5), 1144-1154.

Nyffenegger, P. \& Frohlich, C., 2000. Aftershock occurrence rate decay properties for intermediate and deep earthquake sequences, Geophys. Res. Lett., 27(8), 1215-1218.

Ogata, Y., 1983. Estimation of the parameters in the modified Omori formula for aftershock frequencies by the maximum likelihood procedure, J. Phys. Earth, 31(2), 115-124. 
Ogata, Y. \& Katsura, K., 1993. Analysis of temporal and spatial heterogeneity of magnitude frequency distribution inferred from earthquake catalogues, Geophys. J. Int., 113, 727-738.

Ogata, Y. \& Shimazaki, K., 1984. Transition from aftershock to normal activity: the 1965 Rat Islands earthquake aftershock sequence, Bull. seism. Soc. Am., 74(5), 1757-1765.

Pan, J. \& Dziewonski, M., 2005. Comparison of mid-oceanic earthquake epicentral differences of travel time, centroid locations, and those determined by autonomous underwater hydrophone arrays, J. geophys. Res., 110, B07302, doi:10.1029/2003JB002785.

Park, M., Odom, R.I. \& Soukup, D.J., 2001. Modal scattering: a key to understanding oceanic T-waves, Geophys. Res. Lett., 28(17), 3401-3404.

Press, W.H., Teukolsky, S.A., Vetterling, W.T. \& Flannery, B.P., 1996. Numerical Recipes in Fortran 90, Cambridge University Press, Cambridge, U.K.

Rabinowitz, N. \& Steinberg, D.M., 1998. Aftershock decay of three recent strong earthquakes in the Levant, Bull. seism. Soc. Am., 88(6), 1580-1587.

Rubin, A.M., 1995. Propagation of magma-filled cracks, Annu. Rev. Earth Planet. Sci., 23(1), 287-336.

Scholz, H., 1990. The Mechanics of Earthquakes and Faulting, Cambridge University Press, Cambridge, U.K.

Schorlemmer, D., Neri, G., Wiemer, S. \& Mostaccio, A., 2003. Stability and significance tests for b-value anomalies: example from the Tyrrhenian Sea, Geophys. Res. Lett., 30(16), 1835, doi:10.1029/2003GL017335.

Schorlemmer, D., Wiemer, S. \& Wyss, M., 2005. Variations in earthquake-size distribution across different stress regimes, Nature, 437, doi:10.1038/nature04094.

Schroeder, T. \& John, B.E., 2004. Strain localization on an oceanic detachment fault system, Atlantis massif, $30^{\circ} \mathrm{N}$, Mid-Atlantic Ridge, Geochem. Geophys. Geosyst., 5(11), Q11007, doi:10.1029/2004GC000728.

Searle, R.C., Keeton, J.A., Owens, R.B., White, R.S., Mecklenburgh, R., Parsons, B. \& Lee, S.M., 1998. The Reykjanes Ridge: structure and tectonics of a hot-spot-influenced, slow-spreading ridge, from multibeam bathymetry, gravity and magnetic investigations, Earth planet. Sci. Lett., 160(3-4)(3-4), 463-478.

Sella, G.F., Dixon, T.H. \& Mao, A., 2002. REVEL: a model for recent plate velocities from space geodesy, J. geophys. Res., 107(B4), doi:10.1029/2000JB000033.

Sempéré, J.-C. et al., 1995. The Mid-Atlantic Ridge between $29^{\circ} \mathrm{N}$ and $31^{\circ} 30^{\prime} \mathrm{N}$ in the last $10 \mathrm{Ma}$, Earth planet. Sci. Lett., 130(1-4), 45-55.

Shaw, B.E., 1995. Frictional weakening and slip complexity in earthquake faults, J. geophys. Res., 100(B9), doi:10.1029/95JB01306.

Shaw, P.R., 1992. Ridge segmentation, faulting and crustal thickness in the Atlantic ocean, Nature, 358, 490-493.

Singh, S.C. et al., 2006. Discovery of a magma chamber and faults beneath a Mid-Atlantic Ridge hydrothermal field, Nature, 442(7106), 10291032.

Smith, D.K., Tolstoy, M., Fox, C.G., R., B.D., Matsumoto, H. \& Fowler, M.J., 2002. Hydroacoustic monitoring of seismicity at the slow-spreading MidAtlantic Ridge, Geophys. Res. Lett., 29(11), doi:10.1029/2001GL013912.

Smith, D.K., Escartín, J., Cannat, M., Tolstoy, M., Fox, C.G., Bohnenstiehl, D.R. \& Bazin, S., 2003. Spatial and temporal distribution of seismicity along the northern Mid-Atlantic Ridge $\left(15^{\circ}-35^{\circ} \mathrm{N}\right)$, J. geophys. Res., 108(B3), 2167, doi:10.1029/2002JB001964.

Smith, D.K., Cann, J.R. \& Escartín, J., 2006. Widespread active detachment faulting and core complex formation near $13^{\circ} \mathrm{N}$ on the Mid-Atlantic Ridge, Nature, 442(7101), 440-443.

Smith, D.K., Escartín, J., Schouten, H. \& Cann, J.R., 2008. Fault rotation and core complex formation: significant processes in seafloor formation at slow-spreading mid-ocean ridges (Mid-Atlantic Ridge, $\left.13^{\circ}-15^{\circ} \mathrm{N}\right)$, Geochem. Geophys. Geosyst., 9(03), Q03003, doi:10.1029/2007GC001699.

Sohn, R.A., Thomson, R.E., Rabinovich, A.B. \& Mihaly, S.F., 2009. Bottom pressure signals at the TAG deep-sea hydrothermal field: evidence for short-period, flow-induced ground deformation, Geophys. Res. Lett., 36(19), L19301, doi:10.1029/2009GL040006.

Talandier, J. \& Okal, E.A., 1998. On the mechanism of conversion of seismic waves to and from T waves in the vicinity of island shores, Bull. seism. Soc. Am., 88, 621-632.

Thibaud, R., Gente, P. \& Maia, M., 1998. A systematic analysis of the Mid-Atlantic Ridge morphology and gravity between $15^{\circ} \mathrm{N}$ and $40^{\circ} \mathrm{N}$ : constraints of the thermal structure, J. geophys. Res., 103(B10), 24223-24 243.

Tolstoy, M., Harding, A.J. \& Orcutt, J.A., 1993. Crustal thickness on the Mid-Atlantic Ridge: bull's-eye gravity anomalies and focused accretion, Science, 262(5134), 726-729.

Tucholke, B., Lin, J. \& Kleinrock, M., 1998. Megamullions and mullion structure defining oceanic metamorphic core complexes on the MidAtlantic Ridge., J. geophys. Res., 103(B5), 9857-9866.

Utsu, T., Ogata, Y. \& Matsu'ura, R.S., 1995. The centenary of the Omori formula for a decay law of aftershock activity, J. Phys. Earth, 43, 1-33.

Wiemer, S. \& Wyss, M., 2002. Mapping spatial variability of the frequencymagnitude distribution of earthquakes, $A d v$. geophys., 45, 259-302.

Wiemer, S., Gerstenberger, M. \& Hauksson, E., 2002. Properties of the aftershock sequence of the $1999 \mathrm{Mw} 7.1$ Hector Mine earthquake: implications for aftershock hazard, Bull. seism. Soc. Am., 92(4), 12271240 .

Williams, C.M., Stephen, R.A. \& Smith, D.K., 2006. Hydroacoustic events located at the intersection of the Atlantis $\left(30^{\circ} \mathrm{N}\right)$ and Kane $\left(23^{\circ} 40^{\prime} \mathrm{N}\right)$ transform faults with the Mid-Atlantic Ridge, Geochem. Geophys. Geosyst., 7(6), Q06015, doi:10.1029/2005GC001127.

Woessner, J. \& Wiemer, S., 2005. Assessing the quality of earthquake catalogues: estimating the magnitude of completeness and its uncertainty, Bull. seism. Soc. Am., 95(2), 684-698.

Wyss, M., Hasegawa, A. \& Nakajima, J., 2001a. Source and path of magma for volcanoes in the subduction zone of northeastern Japan, Geophys. Res. Lett., 28(9), 1819-1822.

Wyss, M., Klein, F., Nagamine, K. \& Wiemer, S., 2001b. Anomalously high b-values in the south flank of Kilauea volcano, Hawaii: evidence for the distribution of magma below Kilauea's east rift zone, J. Volc. Geother. Res., 106(1-2), 23-37.

Yang, Y. \& Forsyth, D.W., 2003. Improving epicentral and magnitude estimation of earthquakes from T-phases by considering the excitation function, Bull. seism. Soc. Am., 93, 2106-2122. 